Rodrigo Cerqueira Borges

\title{
Associação entre a degradação muscular e a força muscular em pacientes que desenvolveram sepse grave e choque séptico
}

Tese apresentada à Faculdade de Medicina da Universidade de São Paulo para obtenção do título de Doutor em Ciências

Programa de Ciências Médicas

Área de concentração: Processos Inflamatórios e Alérgicos

Orientador: Prof. Dr. Francisco Garcia Soriano

São Paulo 
Rodrigo Cerqueira Borges

\section{Associação entre a degradação muscular e a força muscular em pacientes que desenvolveram sepse grave e choque séptico}

Tese apresentada à Faculdade de Medicina da Universidade de São Paulo para obtenção do título de Doutor em Ciências

Programa de Ciências Médicas

Área de concentração: Processos Inflamatórios e Alérgicos

Orientador: Prof. Dr. Francisco Garcia Soriano

São Paulo 


\section{Dados Internacionais de Catalogação na Publicação (CIP)}

Preparada pela Biblioteca da

Faculdade de Medicina da Universidade de São Paulo

Creprodução autorizada pelo autor

Borges, Rodrigo Cerqueira

Associação entre a degradação muscular e a força muscular em pacientes que desenvolveram sepse grave e choque sêptico/Rodrigo Cerqueira Borges. -- São Paulo, 2018.

Tese (doutorado) - -Faculdade de Medicina da Universidade de São Paulo.

Programa de Ciências Mëdicas. Ärea de

Concentração: Processos Inflamatórios e Alërgicos.

orientador: Francisco Garcia Soriano.

Descritores: 1.Sepse 2.Força muscular 3. Inflamação 4.Ultrassonografia 5. Unidade de terapia intensiva 6.Proteólise

USP/FM/DBD - 056/18

Responsável: Kátia Maria Bruno Ferreira - CRB-8/6008 
Dedicatória

Dedico este trabalho com todo amor e carinho aos meus filhos por me ensinarem o sentido da palavra compartilhar, principalmente, o tempo, a paciência e o amor!!!! 


\section{Agradecimentos}

Aos meus pais, Adolfo Quintino Borges e Raquel Cerqueira Quintino Borges, por tudo o que vocês me ensinaram e ajudaram nesta vida, sem o apoio de vocês nunca conseguiria ter alcançado mais este sonho. Apesar da distância sei que vocês sempre estiveram comigo.

Ao Prof Dr. Francisco Garcia Soriano, pela orientação e dedicação nesta longa jornada. Sempre me lembrarei das observações sensatas, objetivas e acima de tudo, do respeito e valorização das minhas opiniões.

Aos fisioterapeutas, enfermeiros e técnicos de enfermagem da UTI e da enfermaria da clínica médica do Hospital Universitário da USP que sempre me ajudaram nesta longa jornada, meus sinceros agradecimentos.

Aos pacientes que participaram deste estudo, motivo maior da pesquisa. Agradeço a colaboração que me foi dada, mesmo em momentos desagradáveis de suas vidas.

E a Deus por dar sentido a vida. 


\section{SUMÁRIO}

\section{LISTA DE SIGLAS}

\section{LISTA DE ABREVIATURAS}

\section{LISTA DE FIGURAS}

\section{LISTA DE TABELAS}

\section{RESUMO}

\section{ABSTRACT}

1. INTRODUÇÃO............................................................................... 1

2. OBJETIVOS..................................................................................... 7

2.1. Objetivos primários....................................................................... 7

2.2. Objetivos secundários.................................................................. 7

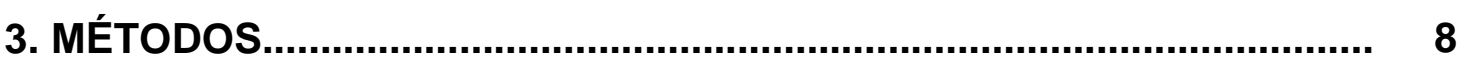

3.1. Desenho do estudo........................................................................ 10

3.2. Variáveis analisadas durante estudo............................................. 11

3.2.1. Variáveis clínicas................................................................. 11

3.2.2. Área de secção transversa do reto femoral............................... 12

3.2.3. Amostras de sangue............................................................ 14

3.2.4. Avaliação diária do despertar................................................ 15

3.2.5. Testes de força muscular..................................................... 15

3.3. Análise estatística......................................................................... 16

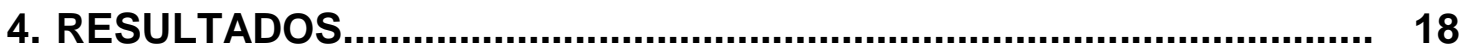

5. DISCUSSÃO....................................................................................... 40

5.1. Aferição da área de secção transversa do reto femoral................. 42

5.2. Fraqueza muscular na sepse...................................................... 43

5.3. Fatores associados à degradação muscular.............................. 45

5.4. Aferições clínicas da força muscular e suas associações.............. 46 
5.5. Marcadores bioquímicos.............................................................. 47

6. CONCLUSÕES................................................................................... 50

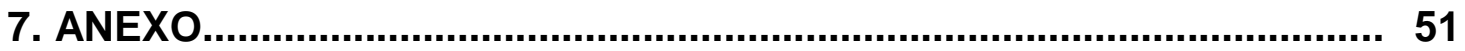

8. REFERÊNCIAS BIBLIOGRÁFICAS................................................. 52 


\begin{tabular}{|c|c|}
\hline AVE & Acidente Vascular Encefálico \\
\hline ASTrf & Área de Secção Transversa do Reto Femoral \\
\hline CK & Creatinoquinase \\
\hline $\mathrm{CCl}$ & Coeficiente de Correlação Intraclasse \\
\hline DPOC & Doença Pulmonar Obstrutiva Crônica \\
\hline ELISA & Enzime-Linked Immunoassay \\
\hline ERAS & Escala de Richmond de Agitação-Sedação \\
\hline FNT- $\alpha$ & Fator de Necrose Tumoral-Alfa \\
\hline HU-USP & Hospital Universitário da Universidade de São Paulo \\
\hline IMC & Índice de Massa Corpórea \\
\hline MRC & Medical Research Council \\
\hline pH & Potencial hidrogeniônico \\
\hline $\mathrm{PaCO}_{2}$ & Pressão Arterial de Gás Carbônico \\
\hline PAM & Pressão Arterial Média \\
\hline $\mathrm{PaO}_{2}$ & Pressão Arterial de Oxigênio \\
\hline $\mathrm{PaO}_{2} / \mathrm{FiO}_{2}$ & Pressão Arterial de Oxigênio/Fração Inspirada de Oxigênio \\
\hline PAS & Pressão Arterial Sistólica \\
\hline RNI & Razão Normalizada Internacional \\
\hline SRQV & Saúde Relacionada à Qualidade de Vida \\
\hline SOFA & Sepsis-related Organ Failure Assessment \\
\hline SAPS 3 & Simplified Acute Physiology Score 3 \\
\hline SDRA & Síndrome do Desconforto Respiratório Agudo \\
\hline UTI & Unidade de Terapia Intensiva \\
\hline VNI & Ventilação Não Invasiva \\
\hline
\end{tabular}




$\begin{array}{ll}\text { bpm } & \text { batimentos por minuto } \\ \mathrm{cm}^{2} & \text { centímetro quadrado } \\ \text { et al } & \text { e outros } \\ \mathrm{g} / \mathrm{dl} & \text { grama/decilitro } \\ { }^{\circ} \mathrm{C} & \text { graus centígrados } \\ \mathrm{Kg} & \text { Kilograma } \\ \mathrm{Kg} / \mathrm{m}^{2} & \text { Kilograma/metro quadrado } \\ > & \text { maior que } \\ \mathrm{MHz} & \text { mega-hertz } \\ < & \text { menor que } \\ \mu \mathrm{cg} & \text { micrograma } \\ \mu \mathrm{cg} / \mathrm{kg} & \text { micrograma/kilograma } \\ \mathrm{mEq} / \mathrm{L} & \text { miliequivalentes por litro } \\ \mathrm{mg} / \mathrm{dl} & \text { miligrama/decilitro } \\ \mathrm{ml} / \mathrm{kg} / \mathrm{h} & \text { mililitros/kilo/hora } \\ \mathrm{mm}{ }^{3} & \text { milímetros cúbicos } \\ \mathrm{mmHg} & \text { milímetros de mercúrio } \\ \mathrm{mM} & \text { milimoles } \\ \mathrm{ng} / \mathrm{mL} & \text { nanograma/mililitro } \\ \% & \text { porcentagem } \\ \mathrm{Unidades} / \mathrm{Kg} & \text { Unidades/ kilograma } \\ \mathrm{U} / \mathrm{L} & \text { Unidades por litro } \\ & \end{array}$




\section{LISTA DE FIGURAS}

Figura 1 - Área de secção transversa do reto femoral pela ultrassonografia.

Figura 2 - Fluxograma de inclusão dos pacientes

Figura 3A - Valores absolutos da área de secção transversa do reto femoral.

Figura 3B - Valores normalizados pelo $2^{\circ}$ dia de internação da área de secção transversa do reto femoral.

Figura 4A - Área de secção transversa do reto femoral nos pacientes submetidos ou não a ventilação mecânica.

Figura 4B - Área de secção transversa do reto femoral nos pacientes submetidos ou não a ventilação mecânica normalizados pelo $2^{\circ}$ dia de internação.

Figura 5 - Força muscular do membros superiores e inferiores avaliada pela escala do Medical Research Council

Figura 6 - Força muscular do membros superiores avaliada pela preensão palmar.

Figura 7 - Correlação linear entre a área de secção transversa do reto femoral e a força de preensão palmar na alta da UTI

Figura 8 - Aldolase analisada dos pacientes durante a internação. 
Figura 9 - Creatinoquinase analisada dos pacientes durante a internação.

Figura 10 - Vitamina D analisada dos pacientes durante a

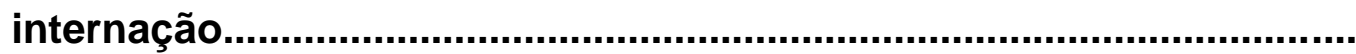




\section{LISTA DE TABELAS}

TABELA 1 - Características clínicas e antropométricas dos pacientes antes da admissão na UTI.

TABELA 2 - Características clínicas dos pacientes na admissão da UTI e durante a permanência hospitalar

TABELA 3 - Exames laboratoriais das primeiras 24 horas de UTI

TABELA 4 - Medicamentos utilizados pelos pacientes durante a permanência na UTI

TABELA 5 - Análise de regressão multivariada das variáveis clínicas analisadas durante o estudo. 


\section{RESUMO}

Borges RC. Associação entre a degradação muscular e a força muscular em pacientes que desenvolveram sepse grave e choque séptico [tese]. São Paulo: "Faculdade de Medicina, Universidade de São Paulo"; 2018.

INTRODUÇÂO: A sepse representa aproximadamente 25\% dos pacientes internados em Unidades de Terapia Intensiva (UTI) e com taxas de mortalidade de 20 a $40 \%$. Além disso, os pacientes sépticos podem apresentar aguda e tardiamente disfunções de órgãos e alterações da musculatura esquelética comprometendo a recuperação na UTI e, posteriormente, a sua saúde relacionada à qualidade de vida. Atualmente, a ultrassonografia tem demonstrado ser uma ferramenta capaz de avaliar a degradação da musculatura esquelética em pacientes críticos. Em pacientes sépticos não se estudou a relação de degradação muscular com testes clínicos de força muscular e aferições bioquímicas. OBJETIVOS: Quantificar a área de secção transversa do reto femoral e a força muscular a beira leito em pacientes que desenvolveram sepse grave e choque séptico. Avaliar associação entre a área de secção transversa do reto femoral e a força muscular em pacientes sépticos. MÉTODOS: Coorte prospectiva que avaliou 37 pacientes na UTI com sepse grave ou choque séptico. A medida da área de secção transversa do reto femoral foi realizada através da ultrassonografia no dia seguinte ao início da sepse e acompanhada durante a internação. Os pacientes foram submetidos a testes clínicos de força muscular (escala do Medical Research Council e a força de preensão palmar) à medida que pudessem compreender comandos verbais. Amostras de sangue foram coletadas para análise de enzimas e hormônio após a admissão no estudo e durante a internação. RESULTADOS: Houve um declínio da área de secção transversa do reto femoral de $5,1(4,4-5,9) \mathrm{cm}^{2}$ no $2^{\circ}$ dia de UTI para $4,4(3,6-5,0) \mathrm{cm}^{2}$ e $4,3(3,7-$ $5,0) \mathrm{cm}^{2}$ na alta da UTI e na alta hospitalar, respectivamente $(p<0,05)$. Por outro lado, os testes clínicos de força apresentaram um aumento na escala do Medical Research Council de 48,0 (36,0-56,0) pontos para 60,0 $(48,0-60,0)$ pontos na alta da UTI, este aumento foi mantido até a alta hospitalar em 60,0 $(52,0-60,0)$ pontos $(p<0,05)$. Em relação à força de preenssão palmar os pacientes apresentavam média de $42,1 \pm 21,9 \%$ do predito no $1^{\circ}$ dia de avaliação e este valor aumentou para $65,9 \pm 20,3 \%$ do predito no dia da alta hospitalar $(p<0,05)$. Houve uma associação da área de secção transversa do reto femoral e das avaliações clínicas de força muscular durante a permanência na UTI. Aumentos no escore de lesão orgânica (SOFA) no $3^{\circ}$ dia e ser do sexo masculino apresentaram-se como fatores independentes para a degradação muscular, assim como, o SOFA do $3^{\circ}$ dia com a fraqueza muscular. CONCLUSÃO: O estudo demonstrou que a sepse pode levar a uma degradação muscular em apenas alguns dias de UTI, associada há uma recuperação incompleta da força muscular ao longo da internação. Além disso, testes clínicos de força muscular se associaram com a degradação muscular durante a internação hospitalar. 
Descritores: sepse; força muscular; inflamação; ultrassonografia; unidade de terapia intensiva; proteólise. 


\section{ABSTRACT}

Borges RC. Association between muscle wasting and muscle strength in patients who developed severe sepsis and septic shock [thesis]. São Paulo: "Faculdade de Medicina, Universidade de São Paulo"; 2018.

INTRODUCTION: Sepsis represents $25 \%$ of patients in the intensive care unit (ICU) with mortality rate of 20 to $40 \%$. In addition, septic patients can present early or lately organ dysfunction and skeletal muscles alterations that reduce patient recovery and compromises health-related to quality of life. Currently, ultrasound has been shown to be a tool capable of evaluating skeletal muscle degradation in critical patients. There are no studies in septic patients about the relation of muscle degradation with clinical tests and blood biochemistry analysis. OBJECTIVES: To quantify the rectus femoris cross-sectional area and muscle strength at the bedside in patients who developed severe sepsis and septic shock. To assess the association between the rectus femoris crosssectional area and muscle strength in septic patients. METHODS: Prospective cohort who evaluated 37 patients in the intensive care unit with severe sepsis or septic shock. The measurement of rectus femoris cross-sectional area was performed by ultrasonography on the day after the onset of sepsis and followed up during hospitalization. Patients underwent clinical tests of muscle strength (Medical Research Council scale and handgrip strength) as they could understand verbal commands. Blood samples were collected for enzyme and hormone analysis after admission to the study and during hospitalization. RESULTS: There was a decline in rectus femoris cross-sectional area from 5.1 (4.4-5.9) $\mathrm{cm}^{2}$ on the 2nd day of ICU to $4.4(3.6-5.0) \mathrm{cm}^{2}$ and $4.3(3.7-5.0) \mathrm{cm}^{2}$ at ICU discharge and at hospital discharge, respectively $(\mathrm{p}<0.05)$. In contrast, strength tests showed an increase in the scale of the Medical Research Council from $48.0(36.0-56.0)$ to 60.0 (48.0-60.0) points in ICU discharge, this increase was maintained until hospital discharge reaching 60.0 (52.0-60.0) points $(p<0.05)$. In relation to the handgrip strength, patients presented a mean of 42.1 $\pm 21.9 \%$ of predicted on the 1 st day of evaluation and this value increased to $65.9 \pm 20.3 \%$ of predicted on the day of hospital discharge $(p<0.05)$. There was an association between the rectus femoris cross-sectional area and clinical assessments of muscle strength during ICU stay. Increases in the organic lesion score (SOFA) on the 3rd day and being male presented as independent factors for muscle degradation, as well as the SOFA of the 3rd day with muscle weakness. CONCLUSION: The study demonstrated that sepsis can lead to muscle degradation in only a few days of ICU, associated with an incomplete recovery of muscle strength throughout hospitalization. In addition, clinical trials of muscle strength were associated with muscle degradation during hospital stay.

Descriptors: sepsis; muscle strength; inflammation; ultrasonography; intensive care unit; proteolysis. 


\section{INTRODUÇÃO}

A sepse é uma síndrome clínica definida pela presença de disfunção orgânica, ameaçadora à vida, secundária à resposta desregulada do organismo à infecção ${ }^{1,2}$. Esta doença representa um problema clínico de relevância em unidades de terapia intensiva (UTI), devido a sua morbidade, letalidade e ao elevado custo financeiro. Sua incidência anual tem aumentado de maneira preocupante nas últimas décadas, saltando de 82,7 casos a cada 100.000 habitantes no ano de 1979 para 240,4 casos em $2000^{3}$. No Brasil, a incidência de sepse nas UTIs também é elevada sendo de 57 casos para cada 1000 pacientes-dia, com uma taxa de mortalidade de $52,2 \%$ nos casos mais graves ${ }^{4}$. Além disso, os custos diretos ao tratamento destes pacientes em UTIs, tanto do setor público quanto privado, são onerosos e chegam a quase 10,000 dólares ${ }^{5}$.

O aumento na incidência e na taxa de mortalidade da sepse tem sido atribuído a inúmeros fatores como: 1- a maior expectativa de vida da população mundial; 2- aumento do número de procedimentos invasivos para diagnósticos e monitorização de pacientes em estado grave; 3- emergência de microrganismos resistentes a antibióticos; 4- o número crescente de pacientes imunodeprimidos, tais como, portadores de neoplasias, transplantes de órgãos, pacientes com a síndrome da imunodeficiência adquirida e doenças debilitantes, como por exemplo, diabetes mellitus, alcoolismo e desnutrição que aumentam a predisposição às infecções ${ }^{6-11}$.

Nos últimos anos, uma campanha mundial denominada "Campanha sobrevivendo a sepse" criada por sociedades médicas vem orientando as melhores evidências científicas disponíveis com o objetivo de reduzir a 
mortalidade nos próximos anos ${ }^{12}$. Apesar dos resultados positivos obtidos até 0 momento em relação à mortalidade ${ }^{13}$, os sobreviventes podem ser comprometidos por disfunções na saúde relacionada à qualidade de vida $(\mathrm{SRQV})^{14-15}$, declínio do estado funcional ${ }^{16}$, fraqueza e degradação muscular ${ }^{17-}$ 18

A degradação muscular é um problema comum em pacientes sépticos, independentemente do suporte nutricional adequado ${ }^{19-22}$. Esta perda de massa muscular muitas vezes é mascarada pela retenção hídrica que pode acometer 10-20\% do próprio peso corpóreo $^{19}$, dificultando sua avaliação diária na UTI. Nestas circunstâncias, os métodos antropométricos de avaliação da massa corpórea não são aplicáveis como técnicas porque assumem um estado normal de hidratação ${ }^{23}$. Até recentemente, os únicos métodos capazes de mensurar o tecido muscular magro na presença de retenção hídrica grave tem sido a análise in vitro por ativação com nêutrons ${ }^{24}$ ou alterações da fibra muscular usando biópsia muscular ${ }^{20,25-27}$. A primeira envolve 0 uso de radiação e geralmente não está disponível e a última é invasiva, necessita expertise no assunto e consome tempo. Além disso, ambas são usadas somente no ambiente de pesquisa. Diferentemente destas técnicas, o ultrassom surge como uma ferramenta simples capaz de avaliar a degradação muscular em pacientes internados na UTI.

O ultrassom tem como vantagens ser um método prático, não invasivo, disponível a beira leito e produz mensurações acuradas ${ }^{18,28}$ da musculatura esquelética em comparação a outros métodos de imagem (tomografia e ressonância ${ }^{28-30}$. Campbell et al. ${ }^{28}$ quantificaram através da ultrassonografia a degradação muscular em pacientes edemaciados com falência de múltiplos 
órgãos. Os autores identificaram três locais onde a espessura do músculo poderia ser facilmente mensurada em pacientes inconscientes na posição supina e, descreveram uma taxa de degradação muscular variando de 2 a $9 \%$ ao $\mathrm{dia}^{28}$. Um segundo estudo utilizando o ultrassom também foi capaz de identificar a presença de degradação muscular em pacientes críticos edemaciados $^{18}$. Apesar destes resultados promissores no estudo da degradação muscular, ainda não são conhecidos os resultados da perda de massa muscular visualizada pelo ultrassom sobre desfechos clínicos como a fraqueza muscular em estudos envolvendo seres humanos em sepse.

A fraqueza muscular geralmente é detectada clinicamente quando os pacientes estão se recuperando da fase aguda da doença e ao despertarem, apresentam-se extremamente debilitados. Esta disfunção pode se manifestar desde um comprometimento leve da musculatura respiratória ${ }^{31}$ até, nos casos mais graves, a uma paralisia total dos membros ${ }^{32}$. Estudos clínicos aplicando mensurações objetivas da função muscular encontraram uma grande incidência de fraqueza muscular ${ }^{33-37}$. Investigações eletrofisiológicas revelam anormalidades neuromusculares em quase $70 \%$ dos pacientes sépticos ${ }^{38}$. Em modelos experimentais o declínio da força ocorreu dentro de algumas horas após a indução da sepse e foi rapidamente progressiva ${ }^{39}$, podendo acometer mais de $50 \%$ da capacidade de gerar força dos músculos respiratórios e dos membros $^{40}$. Além disso, trabalhos mais recentes têm demonstrado que a fraqueza muscular pode evoluir para uma recuperação lenta e incompleta no decorrer de meses a anos ${ }^{41,42}$.

A origem da fraqueza muscular é multifatorial e pode ser ocasionada pelo uso de fármacos ${ }^{43}$, estados hiperinsulinêmicos ${ }^{44}$, o desuso ${ }^{45}$, o stress 
oxidativo $^{46}$ e a inflamação sistêmica ${ }^{47}$ presente na sepse. Um estudo experimental administrando fator de necrose tumoral - alfa (FNT- $\alpha$ ), uma citocina com características pró-inflamatória, observou o surgimento de fraqueza muscular ${ }^{48}$. Neste estudo demonstrou-se que o FNT- $\alpha$ diminui diretamente a força tetânica ${ }^{49}$ e também induz a produção de oxidantes capazes de mediar à degradação e aumentar a proteólise muscular ${ }^{50-53}$. Desta forma, estes dados experimentais corroboram o papel da inflamação sistêmica nas alterações musculoesqueléticas ${ }^{50-53}$. Citocinas presentes na sepse têm sido relacionadas ao desenvolvimento de caquexia ${ }^{54}$, através da disfunção endotelial levando a apoptose dos miócitos, redução da massa muscular e fraqueza muscular. A inflamação e outros fatores têm influência na origem da fraqueza muscular, contudo, não se sabe o tamanho do papel de cada um destes fatores isoladamente.

Atualmente, os métodos para o diagnóstico da fraqueza muscular na UTI mais utilizados são: os testes neurofisiológicos especializados, os exames de força muscular dos membros superiores e inferiores do Medical Research Council $(M R C)$ e a dinamometria através da força de preensão palmar ${ }^{55}$. Os testes neurofisiológicos, como a eletroneuromiografia, consomem tempo, são tecnicamente difíceis de serem realizados, caros e não estão disponíveis em todas as UTIs ${ }^{56,57}$. Por outro lado, os exames de força muscular podem ser feitos por diversos profissionais, são baratos e reprodutíveis. Estes exames de força muscular necessitam apenas que o paciente consiga compreender 0 comando do terapeuta e executem o movimento do grupo muscular avaliado ${ }^{55}$. Ali et al. ${ }^{58}$ demonstraram serem métodos simples e rápidos de diagnosticar a fraqueza entre pacientes que necessitaram de 5 dias de ventilação mecânica. 
Pode ser utilizada ainda, como uma ferramenta para definir a paresia adquirida na UTI $55,59,60$. Contudo, nem sempre é possível de se realizar rotineiramente a avaliação da força muscular através da dinamometria e da escala do MRC. Esta dificuldade é devida às alterações do nível de consciência provocadas pela doença, uso de medicamentos e a falta de condições clínicas do paciente na fase inicial da doença. Nestas circunstâncias, o ultrassom torna-se uma ferramenta viável em avaliar a musculatura esquelética, mesmo nas situações em que os pacientes estão inconscientes ou não colaborativos. Porém, a relação entre a fraqueza muscular obtida em avaliações clínicas e a perda de massa magra detectada pela ultrassonografia ${ }^{61}$ necessita ser investigada.

Até o momento, apenas um estudo clínico avaliou a degradação muscular pela ultrassonografia e as suas associações com a força muscular em pacientes sépticos ${ }^{62}$. Neste estudo de apenas 16 pacientes submetidos à ventilação mecânica por mais de 5 dias, não foram observadas associações da espessura da coxa com a força dos extensores de joelho e também da espessura do diafragma com a força muscular respiratória ${ }^{62}$. Estes resultados podem ter ocorrido pela característica transversal do estudo o que não permitiria avaliar as alterações musculares provocadas pela sepse no decorrer do tempo, somente os valores absolutos obtidos naquele momento. Diferentemente dos resultados deste estudo, em outras populações, houve uma correlação significativa da força muscular com as imagens obtidas pelo ultrassom $^{63}$. Desta forma, é possível que ultrassom seja um método capaz de avaliar a beira leito à área de secção transversa do reto femoral em pacientes que desenvolveram sepse grave e choque séptico e que haja uma associação 
entre as alterações musculares observadas pela ultrassonografia e à força muscular presente na sepse durante a permanência na UTI e hospitalar. 


\section{OBJETIVOS}

\subsection{Objetivos primários}

Quantificar a área de secção transversa do reto femoral (ASTrf) em pacientes que desenvolveram sepse grave e choque séptico através da ultrassonografia durante a permanência na UTI e hospitalar;

Avaliar associação entre ASTrf quantificada pelo ultrassom e a força muscular obtida à beira leito durante a permanência na UTI e hospitalar;

\subsection{Objetivos secundários}

Encontrar preditores clínicos associados à degradação muscular e a força muscular dos membros nos pacientes que desenvolveram sepse grave e choque séptico. 


\section{MÉTODOS}

Foi realizado um estudo observacional de coorte prospectivo envolvendo pacientes com sepse grave e choque séptico internados na UTI-Geral do Hospital Universitário da Universidade de São Paulo (HU-USP) entre junho de 2015 a julho de 2016. Foram incluídos no estudo, todos os pacientes consecutivamente encaminhados a UTI com idade acima de 18 anos, de qualquer raça ou gênero e com diagnóstico de sepse grave ou choque séptico com no máximo 24 horas de evolução em outra unidade. Foram incluídos ainda, os pacientes internados na UTI por outras doenças e que desenvolveram sepse grave ou choque séptico com no máximo 48 horas após admissão na UTI.

Os critérios de sepse grave foram definidos de acordo com diretrizes internacionais ${ }^{64}$, ou seja, sepse mais a disfunção de órgãos ou hipoperfusão de tecido induzida por sepse. Os critérios utilizados para determinar a sepse grave foram: a) a hipotensão induzida por sepse com pressão arterial sistólica (PAS) $<90 \mathrm{mmHg}$ ou pressão arterial média (PAM) $<70 \mathrm{mmHg}$ ou uma queda na PAS $>40 \mathrm{mmHg}$ ou menos de dois desvios padrão abaixo do normal para a idade na ausência de outras causas de hipotensão; b) lactato acima dos limites máximos normais laboratoriais; c) diurese $<0,5 \mathrm{~mL} / \mathrm{kg} / \mathrm{hr}$ por mais de 2 horas apesar da ressuscitação volêmica adequada; d) lesão pulmonar aguda com relação pressão arterial de oxigênio/ fração inspirada de oxigênio $\left(\mathrm{PaO}_{2} / \mathrm{FIO}_{2}\right)<250$ na ausência de pneumonia como fonte de infecção; e) lesão pulmonar aguda com $\mathrm{PaO}_{2} / \mathrm{FIO}_{2}<200$ na presença de pneumonia como fonte de infecção; f) creatinina $>2,0 \mathrm{mg} / \mathrm{dL}$; g) bilirrubina $>2 \mathrm{mg} / \mathrm{dL}$; h) contagem de plaquetas 
$<100000 \mathrm{~mm}^{3}$; i) coagulopatia (razão normalizada internacional $(\mathrm{RNI})>1,5$ ). Choque séptico foi definido, pela presença de hipotensão ou hipoperfusão induzida pela sepse refratária à ressuscitação volêmica e com subsequente necessidade de administração de agentes vasopressores. No inicio do estudo, informações clínicas foram obtidas, incluindo as informações necessárias para se tentar determinar o início do quadro infeccioso.

Foram excluídos os pacientes com história de acidente vascular encefálico prévio ou atual com limitação física nos membros, doenças neuromusculares, pacientes que evoluíram com outros tipos de choque associado, lesão medular, politraumatizados com fratura nos membros, queimados, doentes em fase terminal com expectativa de mortalidade dentro de 72 horas. Foram excluídos ainda, os pacientes com tempo de permanência menor do que 72 horas na UTI ou aqueles que não obtivemos a assinatura do termo de consentimento livre e esclarecido.

Após termos incluídos todos os pacientes no estudo uma nova definição de sepse foi criada baseada no melhor entendimento dos mecanismos fisiopatológicos responsáveis pelas disfunções celulares e moleculares relacionadas à sepse e que contribuem para morbidade e mortalidade associadas com essa síndrome ${ }^{1}$. Nesta nova definição, ficou definido sepse como: a disfunção orgânica potencialmente fatal causada por uma resposta imune desregulada a uma infecção ${ }^{1}$. Choque Séptico: sepse acompanhada por profundas anormalidades circulatórias e celulares/metabólicas capazes aumentar a mortalidade substancialmente ${ }^{2}$. Desta forma, o termo sepse grave foi retirado das definições de sepse. E os critérios clínicos utilizados para definir sepse ficaram: suspeita ou certeza de infecção e um aumento agudo de $\geq 2$ 
pontos no escore de lesão orgânica Sepsis-related Organ Failure Assessment (SOFA) (anexo 1) em resposta a uma infecção. Choque Séptico: sepse mais a necessidade de vasopressor para elevar a pressão arterial média acima de 65 $\mathrm{mmHg}$ e lactato $>2 \mathrm{mmol} / \mathrm{L}$ (18 mg/dL) após reanimação volêmica adequada ${ }^{2}$. Todos os pacientes apresentavam os critérios mais atuais de sepse ou choque séptico e, com isso, puderam ser classificados tanto nas definições anteriores ${ }^{64}$ quanto nas atuais ${ }^{1,2}$.

Durante a permanência na UTI todos os pacientes receberam tratamento médico, fisioterapêutico e nutricional de acordo com as práticas preconizadas pela equipe multiprofissional da respectiva unidade. Os pacientes ou seus respectivos responsáveis foram devidamente informados do objetivo do estudo e, caso aceitassem participar, assinaram o Termo de Consentimento Livre e Esclarecido do Comitê de Ética em Pesquisa aprovado com registro CEPHU/USP:1349/14.

\subsection{Desenho do estudo}

Foi considerado o "dia 1" para o início do registro das variáveis clínicas analisadas durante o estudo, as primeiras 24 horas após a admissão na UTI ou as últimas 24 horas naqueles que desenvolveram sepse grave ou choque séptico após 48 horas da admissão na UTI. No dia seguinte (dia 2), foi iniciada a avaliação da ASTrf com o ultrassom sendo que as demais aconteceram nos dias: "4", "6", "alta da UTI" e "alta hospitalar". Além disso, amostras de sangue

venoso foram coletadas nos mesmos dias da avaliação muscular com o ultrassom para análise de hormônio, enzimas e vitamina. Os participantes foram avaliados diariamente, após a admissão no estudo, para avaliar o seu 
estado de consciência e se já eram capazes de compreender os comandos verbais do examinador. Avaliações clínicas de força muscular dos membros superiores e inferiores foram realizadas através da escala do Medical Research Council e da força de preensão palmar no "primeiro dia" na qual os pacientes foram capazes de obedecer aos comandos do examinador e nos seguintes dias: "3", "5", "alta da UTI" e "alta hospitalar".

Os participantes foram avaliados diariamente, após a admissão no estudo, para ver se já estavam acordados e se já eram capazes de compreender os comandos verbais do examinador, caso isto ocorresse, foram submetidos às avaliações clínicas de força muscular dos membros superiores e inferiores através da escala do Medical Research Council e da força de preensão palmar.

\subsection{Variáveis analisadas durante estudo}

\subsubsection{Variáveis clínicas}

Os dados da história clínica atual foram coletados através do prontuário médico, dos exames laboratoriais colhidos e dos controles feitos pela equipe de enfermagem de onde foram extraídas informações da UTI e de toda permanência hospitalar. Os seguintes dados foram coletados: idade, índice de massa corpórea (IMC), sexo, comorbidades, motivo da internação, Simplified Acute Physiology Score $3\left(\right.$ SAPS-3) ${ }^{65,66}$, SOFA ${ }^{67}$ e os sítios de infecção suspeitos ou documentados. Os exames laboratoriais das primeiras 24 horas de UTI registrados foram: bilirrubinas totais e frações, aspartato aminotransferase, alanina aminotransferase, creatinina, uréia, sódio, potássio, lactato, gasometria arterial, glicose, hemograma, cálcio e fósforo. Além disso, 
foi quantificado o tempo de internação na UTI e hospitalar, o tempo de ventilação mecânica e o número de re-intubação daqueles que necessitaram de suporte ventilatório invasivo. Foram coletados ainda, os dados de dias de lesão orgânica, dias de diálise, o uso e a dose total de corticosteroides, drogas vasoativas, sedativos e bloqueadores neuromusculares.

\subsection{2. Área de secção transversa do reto femoral}

A ASTrf foi avaliada com um ultrassom (GE Vivid 7, GE Medical Systems, USA) através de um transdutor linear de alta frequência $(7.5 \mathrm{MHz})$ apropriado para análise das estruturas ${ }^{68}$, semelhante ao método utilizado por outros pesquisadores $^{63,69}$. O transdutor foi colocado perpendicular ao longo do eixo da coxa no seu aspecto superior, a três quintos de distância entre a crista ilíaca superior e a borda superior da patela. Este foi o ponto na coxa que toda a área de secção transversa do reto femoral pode ser visualizada num único campo em todos os indivíduos, sendo que, outros músculos do grupo muscular quadríceps não puderem ser visualizados desta maneira. As imagens foram adquiridas com os indivíduos em posição supina com os membros em repouso em extensão de joelho após 30 minutos nesta posição. Está técnica tem demonstrado uma boa reprodutibilidade inter e intra-observadores ${ }^{63,69-70}$. Uma quantidade de gel de contato próprio para ultrassom foi aplicada para visualização das estruturas e para minimizar a distorção do tecido mole subjacente. Imagens oblíquas foram minimizadas pelo avaliador, utilizando um feedback visual para obter a melhor imagem da ASTrf. A visualização do fêmur foi utilizada para orientação das estruturas. Manobras de contração e relaxamento foram feitas nos pacientes capazes de realizar tais manobras para 
delinear o septo muscular antes da aquisição da imagem. A ASTrf foi calculada por uma técnica planimétrica após a linha ecogênica interna do reto femoral ter sido delineada com um cursor móvel sobre uma imagem congelada (Figura 1). Para padronizar as medidas, a posição do transdutor foi demarcada com caneta para as medições seguintes. A área foi determinada pela média de três medidas com uma variação máxima de $10 \%$ entre elas. Todas as medidas foram realizadas por examinador não médico ao longo do estudo. Este examinador não médico recebeu treinamento por 6 meses de um profissional médico especializado em radiologia e diagnóstico por imagem com grande expertise em ultrassom muscular. Antes do início do estudo, foram utilizados 15 pacientes críticos submetidos à ventilação mecânica selecionados de forma aleatória para determinar o coeficiente de correlação intraclasse $(\mathrm{CCl})$ dos dois examinadores. 
Figura 1. Área de secção transversa do reto femoral pela ultrassonografia

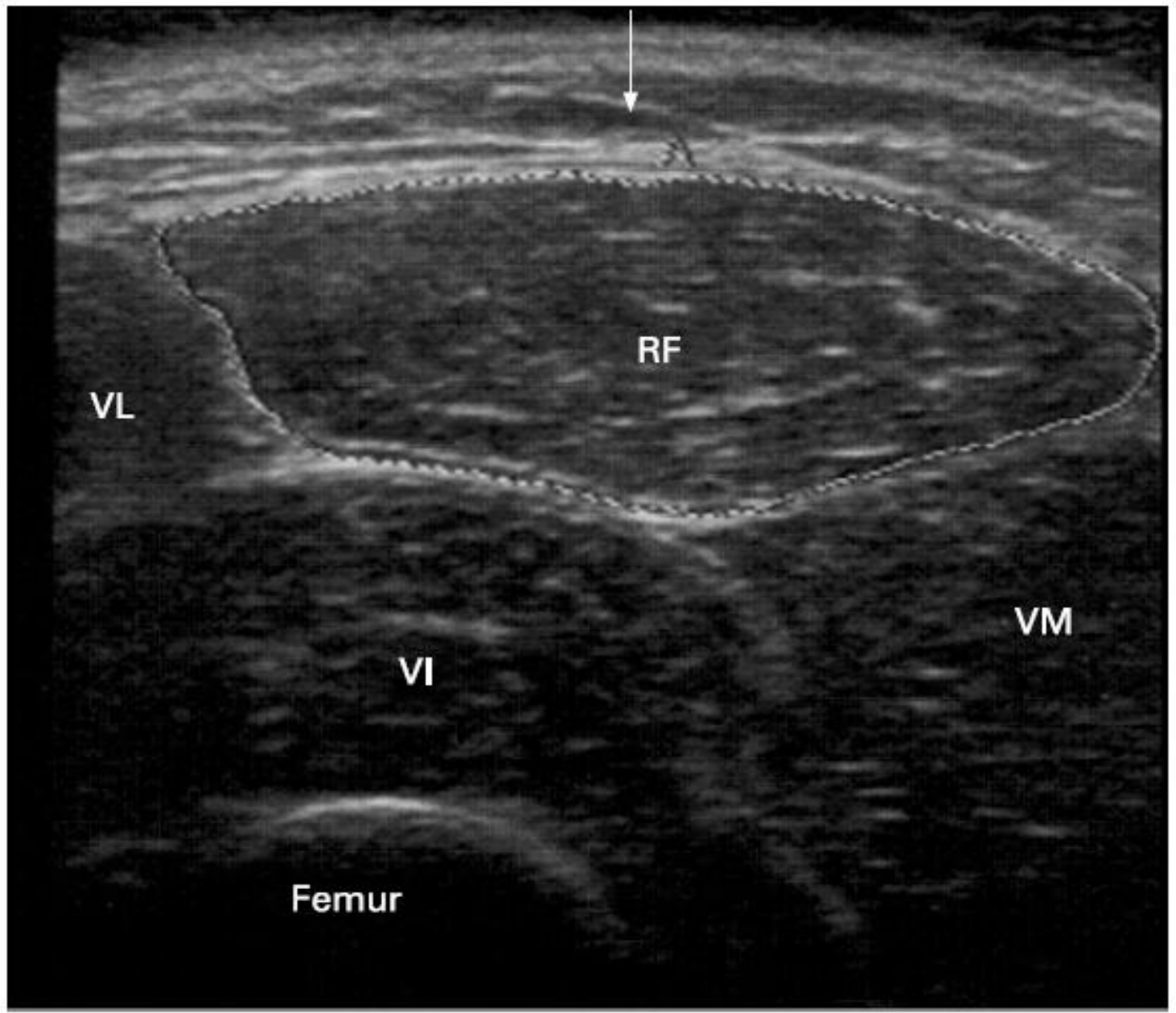

Legenda: Ultrassonografia da área de secção transversa do reto femoral em

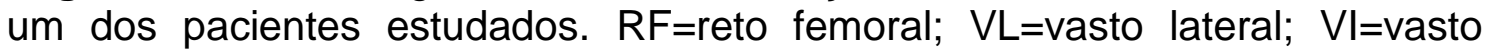
intermédio; VM=vasto medial

\subsubsection{Amostras de sangue}

Amostras de sangue venoso foram coletadas pelo período da manhã antes das refeições e com os pacientes em repouso para análise de enzimas (creatinoquinase (CK) e aldolase) e hormônio (vitamina D) nos mesmos dias das avaliações do ultrassom muscular. As amostras foram centrifugadas e o soro foi armazenado a $-80^{\circ} \mathrm{C}$ para posterior quantificação das enzimas e de hormônio através da técnica de enzime-linked immunoassay (ELISAMyBioSource, EUA). 


\subsubsection{Avaliação diária do despertar}

Os participantes foram avaliados diariamente para verificar se estavam acordados e se eram capazes de compreender os comandos verbais do examinador. Nos indivíduos calmos e acordados (Escala de Richmond de Agitação-Sedação (ERAS) ${ }^{71}$ entre -1 a +1 , a compreensão a comandos verbais foi avaliada baseada na resposta deles a 5 comandos: "Abra (feche) os seus olhos"; "Olhe para mim"; "Abra a boca e coloque a sua língua para fora"; "Mexa a cabeça" e "levante as sobrancelhas quando eu contar até cinco". No primeiro dia que os pacientes responderam 3 destes comandos em 2 avaliações consecutivas com um intervalo de 6 horas, foi considerado o "dia 1" para avaliação da força muscular a beira leito. Estes métodos foram validados para pacientes internados em terapia intensiva ${ }^{55,71-72}$.

\subsubsection{Testes de força muscular}

A avaliação da força muscular, dos membros superiores e inferiores, foi realizada através da escala de força do $M R C$. Seis grupos musculares dos membros superiores (extensão do punho, flexão de cotovelo e abdução do ombro) e dos inferiores (flexão dorsal do pé, extensão do joelho e flexão de quadril) foram testados bilateralmente, a menos que as condições clínicas impedissem de realizá-los. Cada grupo muscular recebeu uma pontuação entre 0 a $5(0=$ nenhuma contração visível ou palpável; $1=$ contração visível e palpável sem movimentação do membro; 2=movimenta o membro, mas não vence a gravidade; $3=$ movimenta contra a gravidade; $4=$ movimenta contra gravidade e uma pequena resistência, $5=$ movimenta contra a gravidade e uma resistência elevada) atingindo um escore total de 60 pontos $^{60}$. 
Imediatamente após aplicação da escala do $M R C$, o mesmo examinador realizou a dinamometria (Takei Physical Fitness Test, modelo T18-Smedley III, Japão) com o intuito de avaliar a força de preensão palmar. Para realização do teste foi solicitado ao paciente à execução de três medidas de preensão palmar, na posição sentada, com o membro superior dominante em flexão de cotovelo a $90^{\circ}$, adução de ombro e punho em posição neutra, sendo considerado para análise o maior valor das tentativas ${ }^{73}$. Antes do início do teste os pacientes realizaram duas tentativas para reduzir o efeito de aprendizado.

\subsection{Análise estatística}

Baseado em dados anteriores ${ }^{63}$ de uma população de indivíduos saudáveis, com uma média de área de seção transversa de reto femoral de $4,63 \pm 1,37 \mathrm{~cm}^{2}$, utilizando o cálculo para inferência de uma média uniamostral, 31 pacientes eram necessários para detectar uma redução de 15\% na média da área de seção transversa do reto femoral com nível de significância de 5\% e um poder de $80 \%$. Além disso, resolvemos aumentar em $20 \%$ o número da amostra devido a perdas que poderiam ocorrer durante o estudo. As variáveis quantitativas foram expressas como média e desvio padrão, exceto, em condições especiais que foram apresentadas em mediana (percentil25percentil75) e as variáveis categóricas foram apresentadas como número total e porcentagem, A distribuição paramétrica dos dados foi avaliada pelo teste de Shapiro-Wilk. Para análise da reprodutibilidade inter-observadores foi utilizado - Coeficiente de Correlação Intraclasse. A correlação entre a ASTrf e da força muscular com as demais variáveis quantitativas do estudo foi feita pela correlação de Spearman. Foi realizado o teste de análise de variância para um 
fator com correção de Bonferroni para avaliação da ASTrf e da força muscular no decorrer do tempo. Um modelo de regressão multivariada foi realizado para o delta (início - final) de variação da área de seção transversa do reto femoral e para porcentagem do predito da força muscular de preensão palmar com as variáveis que apresentaram $p<0,05$, na análise de regressão linear univariada ou nas análises bivariadas. O nível de significância foi estabelecido em 5\% $(p<0,05)$ e a análise estatística foi calculada pelo programa estatístico SPSS 17.0. 


\section{RESULTADOS}

Durante a realização do estudo, foram atendidos na UTI Geral do HUUSP um total de 320 pacientes com diagnóstico de sepse grave ou choque séptico com no máximo 24 horas de evolução em outra unidade ou até 48 horas após admissão na UTI. Destes, 274 pacientes não foram incluídos no estudo pelos seguintes motivos: foram a óbito com menos de 72 horas de internação na UTI ( $n=147)$, apresentavam outros tipos de choque associados ( $n=34$ ), diagnóstico atual ou prévio de AVE com limitação física em um dos membros $(n=33)$, fase terminal da doença $(n=20)$, doenças neuromusculares $(n=12)$ e outro motivos ( $n=28)$ (Figura 2). Um total de 37 pacientes realizaram todas as avaliações de força muscular e do ultrassom muscular até a alta hospitalar e entraram na análise estatística do estudo (Figura 2). 
Figura 2 - Fluxograma de inclusão dos pacientes

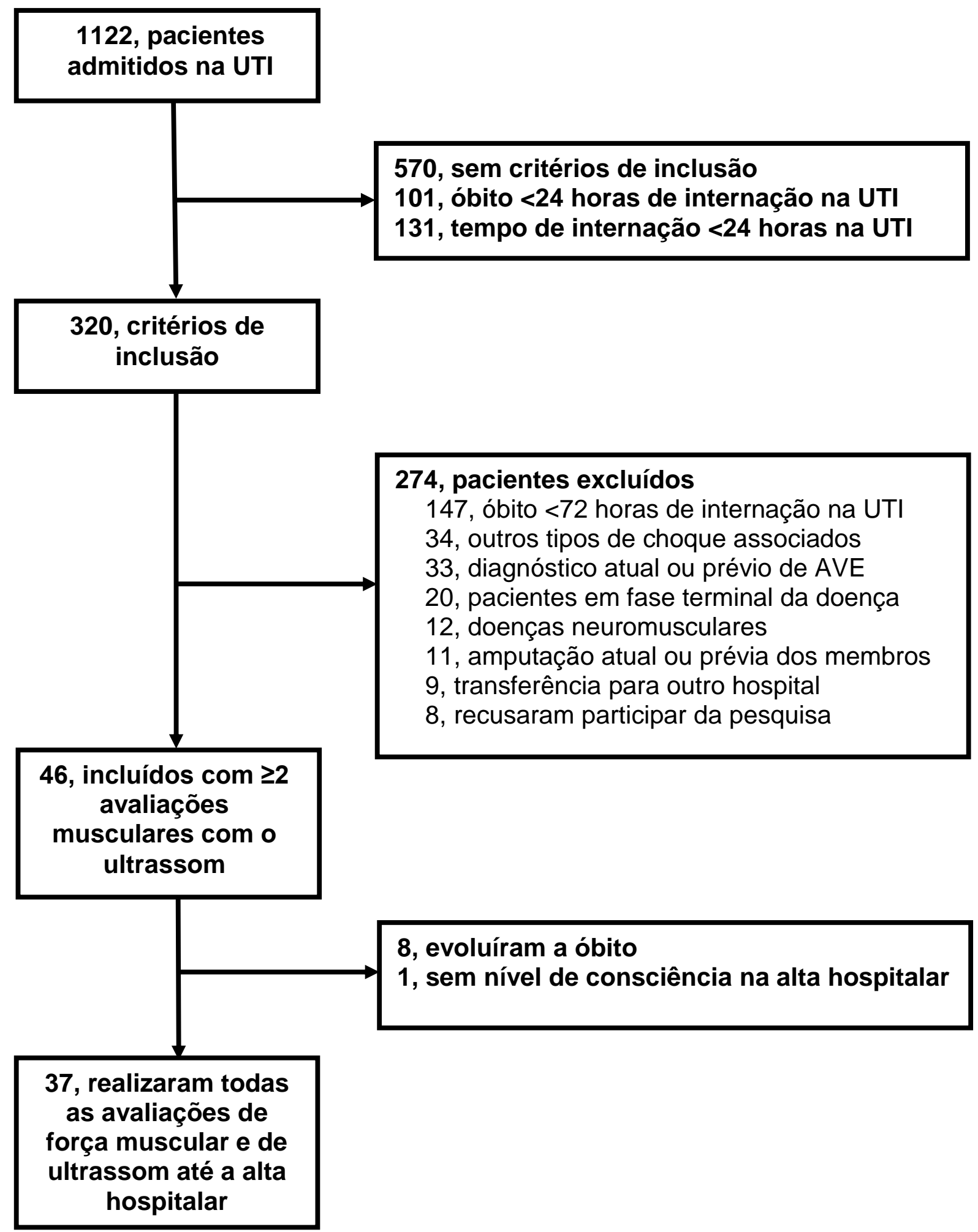

Legenda: UTI, unidade de terapia intensiva; AVE, acidente vascular encefálico 
As características clínicas, antropométricas e as comorbidades dos pacientes antes da admissão na UTI estão descritas na Tabela 1. A maioria dos pacientes era do sexo masculino $(54,1 \%)$ com idade média de $53,3 \pm 18,8$ anos. A comorbidade mais prevalente foi à hipertensão arterial sistêmica em $48,6 \%$ de todos os casos e $29,7 \%$ dos casos eram compostos de pacientes cirúrgicos.

Tabela 1 - Características clínicas e antropométricas dos pacientes antes da admissão na UTI

\begin{tabular}{|c|c|}
\hline Variáveis & Pacientes $(n=37)$ \\
\hline Idade, anos & $53,3 \pm 18,8$ \\
\hline Sexo, masculino $\mathrm{n}(\%)$ & $20(54,1)$ \\
\hline Índice de massa corpórea, $\mathrm{kg} / \mathrm{m}^{2}$ & $25,9 \pm 6,3$ \\
\hline \multicolumn{2}{|l|}{ Comorbidades } \\
\hline Diabetes mellitus, $\mathrm{n}(\%)$ & $10(27,0)$ \\
\hline Insuficiência renal crônica, n (\%) & $11(29,7)$ \\
\hline Hipertensão Arterial Sistêmica, n (\%) & $18(48,6)$ \\
\hline DPOC, n (\%) & $11(29,7)$ \\
\hline Insuficiência Cardíaca Crônica, n (\%) & $9(24,3)$ \\
\hline Índice de Charlson & $1(0,0-3,0)$ \\
\hline \multicolumn{2}{|l|}{ Local de origem } \\
\hline Pronto Socorro, n (\%) & $23(62,2)$ \\
\hline Enfermaria, n (\%) & $6(16,2)$ \\
\hline Centro Cirúrgico, n (\%) & $8(21,6)$ \\
\hline
\end{tabular}


O tempo de internação hospitalar dos pacientes sépticos antes de serem transferidos para UTI foi de 23,0 $(8,0-67,7)$ horas. O principal sítio de infecção foi o sistema respiratório. Aproximadamente, $70 \%$ dos pacientes foram admitidos na UTI com choque séptico e outros 3 evoluíram com choque séptico após a inclusão no estudo segundo as definições anteriores de sepse. De acordo com as novas diretrizes, $59,4 \%$ dos pacientes apresentavam choque séptico na admissão e 1 paciente evoluiu posteriormente. Ao todo, $62,2 \%$ dos pacientes necessitaram de suporte ventilatório invasivo. Destes, 4 pacientes foram traqueostomizados ao longo da permanência na UTI. Concentrados de hemácias foram administrados em aproximadamente $46 \%$ dos pacientes e 35,1\% dos pacientes realizaram diálise. As demais características clínicas dos pacientes na admissão na UTI ou durante a permanência hospitalar estão descritas na tabela 2. 
Tabela 2 - Características clínicas dos pacientes na admissão da UTI e durante a permanência hospitalar

\begin{tabular}{lc} 
Variáveis & Pacientes (n=37) \\
\hline SAPS 3, admissão & $56,4 \pm 10,7$ \\
SOFA, admissão & $8,0(6,0-12,0)$ \\
SOFA, 48 horas & $5,0(2,0-5,0)$ \\
SOFA, 72 horas & $2,0(0,0-2,0)$ \\
Choque séptico na admissão*, $n$ (\%) & $25(67,6)$ \\
Choque séptico na admissão\#, $n$ (\%) & $22(59,4)$ \\
Ventilação mecânica, $n$ (\%) & $23(62,2)$ \\
Dias de ventilação mecânica & $5,0(1,8-8,5)$ \\
SDRA, n (\%) & $6(16,2)$ \\
Utilizaram VNI, $n$ (\%) & $28(75,7)$ \\
Sítio de infecção da sepse & \\
$\quad$ Respiratório & $12(32,4)$ \\
$\quad$ Abdominal & $11(29,7)$ \\
Urinário & $7(18,9)$ \\
Outros & $2(5,4)$ \\
Indefinido & $5(13,5)$ \\
Dias de internação na UTI & $11,6 \pm 9,6$ \\
Dias de internação hospitalar & $22,9 \pm 11,7$
\end{tabular}

\footnotetext{
Legenda: Valores estão apresentados como média \pm desvio padrão ou número total dos pacientes (\%), exceto, em condições especiais descrito em mediana (percentil25-percentil75). SAPS 3=Simplified Acute Physiology Score 3; SOFA=Sequential Organ Failure Assessment; VNI= Ventilação Não Invasiva; UTI= Unidade de Terapia Intensiva; SDRA: Síndrome do Desconforto Respiratório Agudo.*Definições de choque séptico segundo as diretrizes anteriores de sepse ${ }^{64}$. \# Definições de choque séptico segundo as atuais diretrizes de sepse $e^{1,2}$.
} 
Os pacientes apresentavam valores acima ou abaixo dos valores de referência nas primeiras 24 horas de UTI nos seguintes exames: glicemia capilar, lactato, uréia, creatinina, hemoglobina e leucócitos. Os demais exames laboratoriais das primeiras 24 horas de admissão na UTI estão descritos na tabela 3. 
Tabela 3 - Exames laboratoriais das primeiras 24 horas de UTI

\begin{tabular}{|c|c|}
\hline Variáveis & Pacientes $(n=37)$ \\
\hline Glicemia, mg/dl & $148,6 \pm 74,5$ \\
\hline Sódio, mEq/L & $138,7 \pm 6,0$ \\
\hline Potássio, mEq/L & $4,4 \pm 0,9$ \\
\hline Lactato, mg/dl & $15,4(12,0-26,1)$ \\
\hline Tempo de protrombina, INR & $1,2(1,1-1,4)$ \\
\hline Plaquetas, $\mathrm{mm}^{3}(\mathrm{x} 100)$ & $251,8 \pm 151,9$ \\
\hline Fósforo, mg/dL & $3,8 \pm 1,5$ \\
\hline Bilirrubina total, mg/dL & $0,5(0,3-0,8)$ \\
\hline Bilirrubina direta, $\mathrm{mg} / \mathrm{dL}$ & $0,3(0,1-0,6)$ \\
\hline Uréia, mg/dL & $82,6 \pm 65,2$ \\
\hline Creatinina, mg/dL & $1,7(0,9-4,0)$ \\
\hline pH & $7,4 \pm 0,1$ \\
\hline $\mathrm{PaCO}_{2}, \mathrm{mmHg}$ & $37,2 \pm 11,9$ \\
\hline $\mathrm{PaO}_{2}, \mathrm{mmHg}$ & $95,3 \pm 36,6$ \\
\hline Hemoglobina, g/dL & $11,0 \pm 2,7$ \\
\hline Leucócitos, mm³ & $15374,3 \pm 6801,5$ \\
\hline Troponina, ng/mL & $0,06(0,01-0,3)$ \\
\hline Cálcio ionizado, mg/dL & $1,16 \pm 0,1$ \\
\hline Aspartato transaminase, $\mathrm{U} / \mathrm{L}$ & $33,0(20,0-56,0)$ \\
\hline Alanina transaminase, $\mathrm{U} / \mathrm{L}$ & $36,0(22,0-52,0)$ \\
\hline
\end{tabular}

Legenda:Valores estão apresentados como média \pm desvio padrão ou mediana (percentil 25-75). INR=Razão Normalizada Internacional; pH=Potencial Hidrogeniônico; $\mathrm{PaCO}_{2}=$ Pressão Arterial de Gás Carbônico; $\mathrm{PaO}_{2}=$ Pressão Arterial de Oxigênio. 
Durante a permanência na UTI, $7,3 \%$ dos pacientes receberam dobutamina com uma dose total de 456,0 $(238,0-674,0) \mathrm{mg}$ e de propofol de $234,0(175,0-255,0) \mathrm{mg}$. Outros medicamentos utilizados na UTI e suas respectivas doses estão descritos na tabela 4.

Tabela 4 - Medicamentos utilizados pelos pacientes durante a permanência na UTI

\begin{tabular}{lc}
\hline \hline Variáveis & Pacientes $(\mathrm{n}=37)$ \\
\hline Dose total de Noradrenalina, mg/kg & $0,32(0,07-0,78)$ \\
$\quad$ número de pacientes que receberam (\%) & $28,00(75,67)$ \\
Dose total de Vasopressina,unidades/kg & $2,51(1,39-4,10)$ \\
$\quad$ número de pacientes que receberam (\%) & $4,00(10,81)$ \\
Dose total de Dormonid, mg/kg & $6,36(1,14-10,27)$ \\
$\quad$ número de pacientes que receberam (\%) & $20,00(54,05)$ \\
Dose total de Fentanil, $\mu \mathrm{cg} / \mathrm{kg}$ & $63,88(22,86-107,27)$ \\
$\quad$ número de pacientes que receberam (\%) & $21,00(56,75)$ \\
Dose total de Cisatracurium, mg & $677,07(108,0-1183,71)$ \\
$\quad$ número de pacientes que receberam (\%) & $4,00(10,81)$ \\
Dose total de hidrocortisona, mg & $1470,03(750,02-3552,53)$ \\
número de pacientes que receberam (\%) & $14,00(37,83)$ \\
\hline \hline $\begin{array}{l}\text { Legenda: Valores estão apresentados como número total } \\
\text { mediana (percentil25-percentil75). }\end{array}$ &
\end{tabular}


Os pacientes apresentaram um declínio da área de secção transversa do reto femoral de $5,1(4,4-5,9) \mathrm{cm}^{2}$ no $2^{\circ}$ dia de UTI para $4,4(3,6-5,0)$ e $4,3(3,7-$ $5,0)$ na alta da UTI e na alta hospitalar, respectivamente $(p<0,05)$. Houve uma redução em torno de $15 \%$ área de secção transversa do reto femoral em apenas 10 dias de internação na UTI (declínio de 1,50\%/dia) (figura 3A).

Figura 3A. Valores absolutos da área de secção transversa do reto femoral

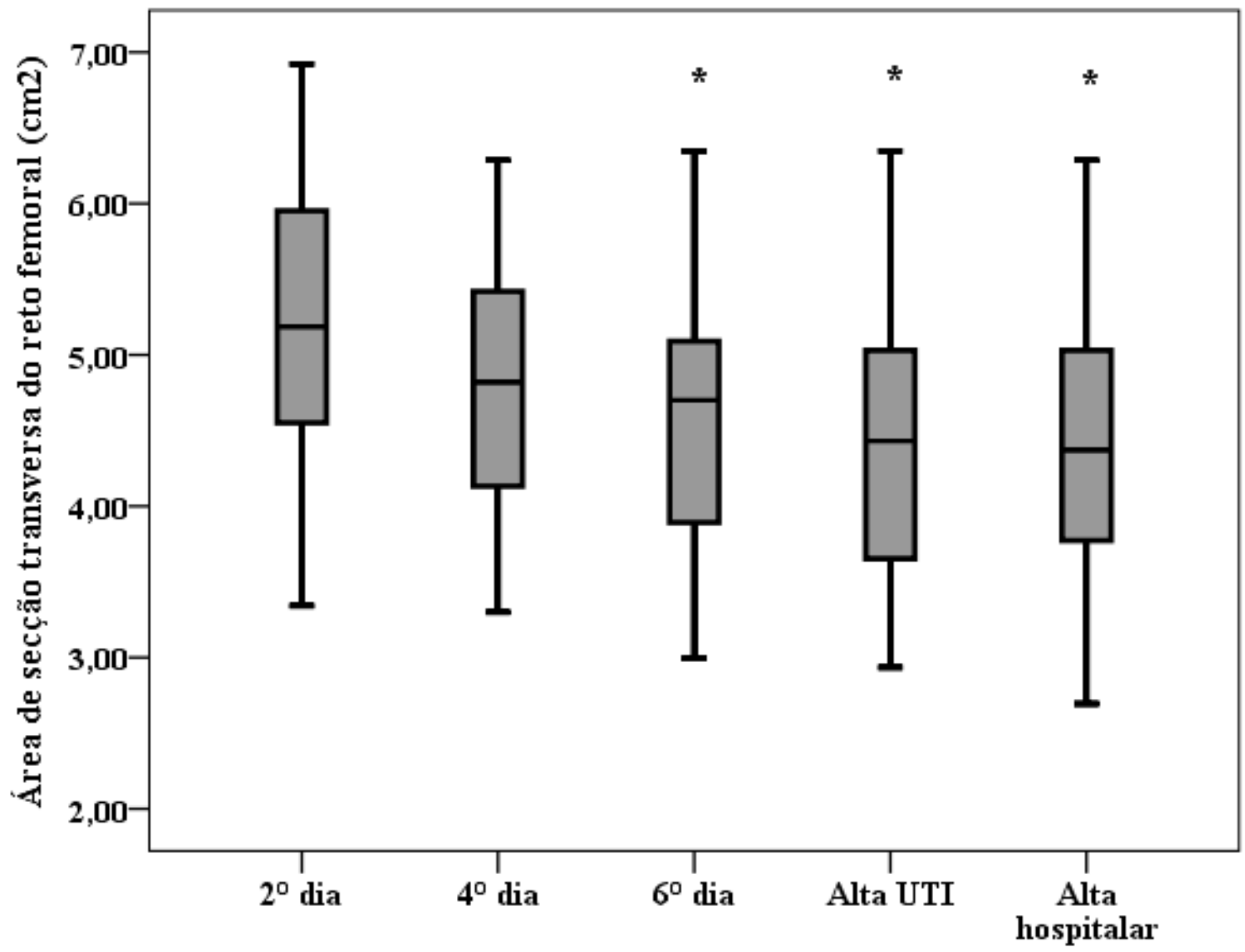

Legenda: Os valores apresentados representam os obtidos na avaliação da área de secção transversa do reto femoral através da ultrassonografia dos 37 pacientes do estudo. $O 2^{\circ}$ dia, $4^{\circ}$ dia, $6^{\circ}$ dia referem-se ao dia de internação na UTI. ${ }^{*} p<0,05=$ comparação ao $2^{\circ}$ dia de UTI. Para comparação da área de secção transversa ao longo do tempo foi utilizada análise de variância de 1 fator com comparações multiplas de Bonferroni. 
Na figura 3B os valores obtidos na área de secção transversa do reto femoral foram divididos pelos obtidos no $2^{\circ}$ dia de internação. Os pacientes apresentaram um declínio significativo a partir do $4^{\circ}$ dia de internação $(p<0,05)$.

Figura 3B. Valores normalizados pelo $2^{\circ}$ dia de internação da área de secção transversa do reto femoral

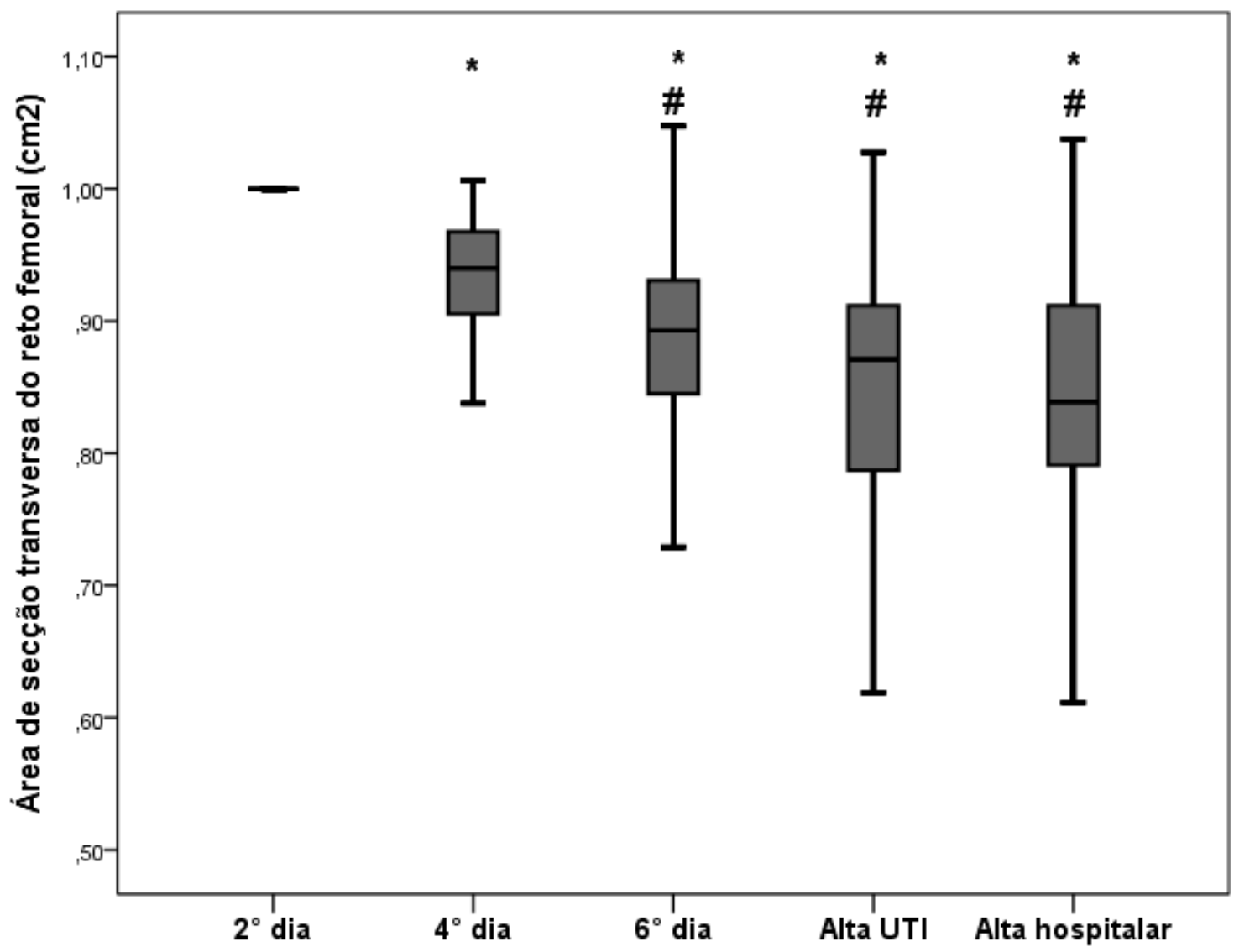

Legenda: Os valores apresentados representam os obtidos na avaliação da área de secção transversa do reto femoral através da ultrassonografia dos 37 pacientes do estudo. Cada valor absoluto da ASTrf foi dividido pelo obtido no $2^{\circ}$ dia de internação para facilitar a visualização das variações da ASTrf. O $2^{\circ}$ dia, $4^{\circ}$ dia, $6^{\circ}$ dia referem-se ao dia de internação na UTI. ${ }^{*} \mathrm{p}<0,05=$ comparação ao $2^{\circ}$ dia de UTI. \# $\mathrm{p}<0,05=$ comparação ao $4^{\circ}$ dia de UTI. Para comparação da área de secção transversa ao longo do tempo foi utilizada análise de variância de 1 fator com comparações multiplas de Bonferroni. 
$\mathrm{Na}$ figura $4 \mathrm{~A}$, foi analisado separadamente a área de secção transversa do reto femoral dos pacientes submetidos ou não a ventilação mecânica ao longo do estudo. Não houve diferença entre os grupos na ASTrf $(p>0,05)$ e, também, da interação entre os grupos (ventilação mecânica x sem ventilação mecânica) e o tempo ( $2^{\circ}$ dia, alta UTI e alta hospitalar). Porém, houve uma redução no decorrer do tempo a partir da alta da UTI em comparação ao $2^{\circ}$ dia $(p<0,05)$. Os pacientes submetidos a ventilação mecânica apresentaram uma redução da área de secção transversa do reto femoral de aproximadamente $17,6 \%$ e naqueles sem ventilação mecânica de 10,0\% em comparação ao $2^{\circ}$ dia.

Para facilitar a visualização das variações da ASTrf nos pacientes submetidos ou não a ventilação mecânica os valores absolutos foram divididos pelos obtidos no $2^{\circ}$ dia de internação (Figura 4B). Houve diferença significativa entre os grupos (ventilação mecânica $x$ sem ventilação mecânica) na ASTrf $(p<0,05)$ e, também, nos tempos $\left(2^{\circ}\right.$ dia, alta UTI e alta hospitalar). Além disso, houve diferença na interação entre os grupos e o tempo $(p<0,05)$. 
Figura 4A. Área de secção transversa do reto femoral nos pacientes submetidos ou não a ventilação mecânica

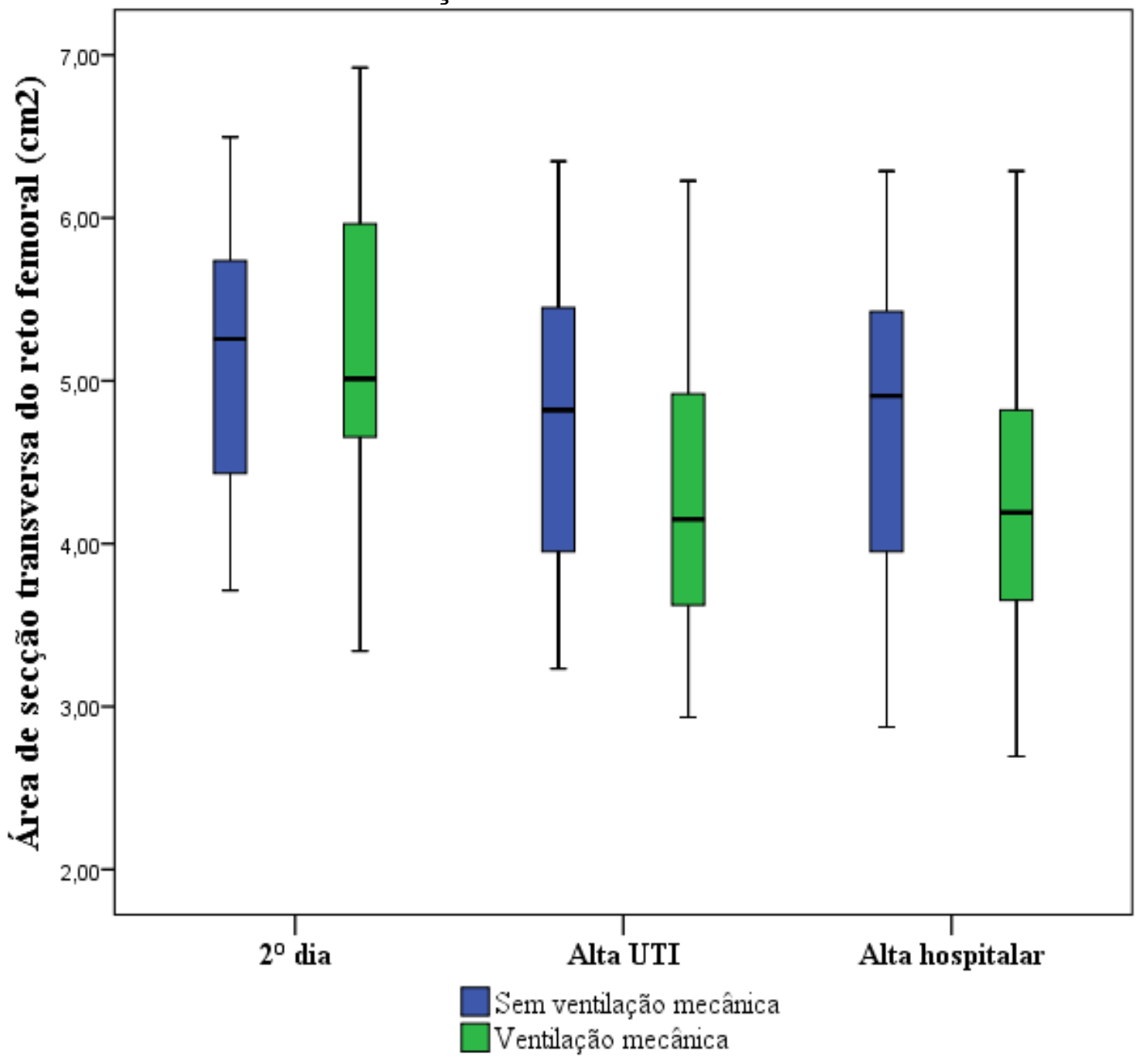

Legenda: Os valores apresentados representam a área de secção transversa do reto femoral através da ultrassonografia ao longo do estudo nos pacientes que foram submetidos ou não ventilação mecanica. $2^{\circ}$ dia = refere-se ao dia após a internação na UTI. Para comparação da área de secção transversa do reto femoral ao longo do tempo e dos grupos foi utilizada análise de variância de 2 fatores com comparações multiplas de Bonferroni. 
Figura 4B. Área de secção transversa do reto femoral nos pacientes submetidos ou não a ventilação mecânica normalizados pelo $2^{\circ}$ dia de internação

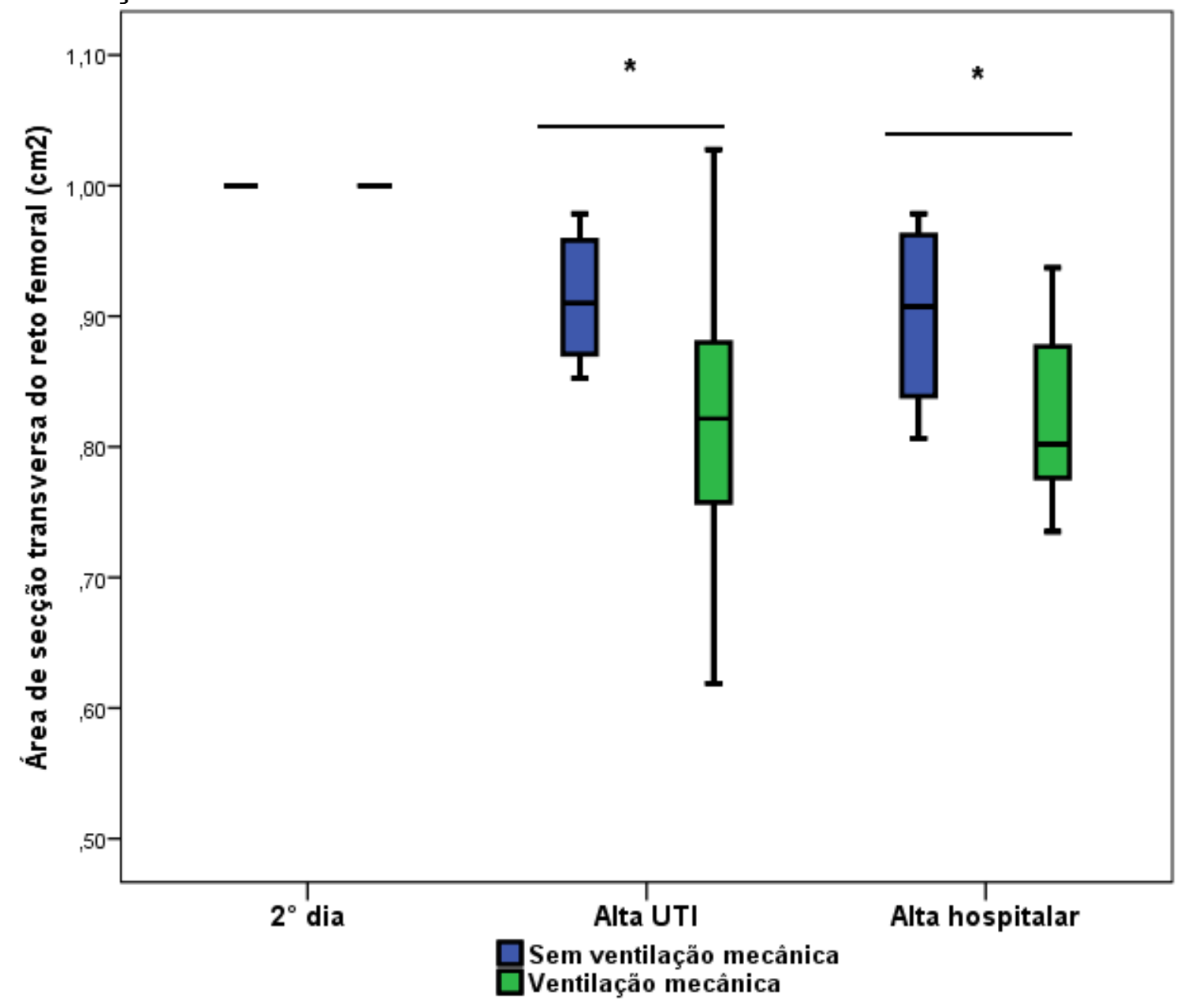

Legenda: Os valores apresentados representam a área de secção transversa do reto femoral através da ultrassonografia ao longo do estudo nos pacientes que foram submetidos ou não ventilação mecanica. Cada valor absoluto da ASTrf foi dividido pelo obtido no $2^{\circ}$ dia de internação para facilitar a visualização das variações da ASTrf $2^{\circ}$ dia $=$ refere-se ao dia após a internação na UTI. Para comparação da área de secção transversa do reto femoral ao longo do tempo e dos grupos foi utilizada análise de variância de 2 fatores com comparações multiplas de Bonferroni.

O coeficiente correlação intraclasse entre os observadores para área de secção tranversa do reto femoral foi realizada em 15 pacientes internados na UTI e houve uma forte correlação com CCI de 0,966 (95\% IC 0,901-0,989). 
Somente um paciente não conseguiu realizar todas as avaliações de força muscular dos membros superiores e inferiores pela escala do MRC e da força de preensão palmar porque não tinha nível de consciência até a alta hospitalar para realização dos testes. No primeiro dia que os pacientes foram considerados aptos à realização dos testes de força muscular eles apresentavam um escore do MRC de 48,0 $(36,0-56,0)$, com uma melhora significativa ao longo da internação $(p<0,05)$ para $60,0(48,0-60,0)$ e $60,0(52,0-$ $60,0)$ na alta da UTI e hospitalar, respectivamente (figura 5). Na alta da UTI, $25,0 \%$ dos pacientes apresentavam ainda valores indicativos de fraqueza muscular (<48 na escala). Não houve diferença na pontuação entre o lado esquerdo e o direito $(p>0,05)$. Também não houve diferença na pontuação entre os grupos musculares dos membros inferiores comparada a dos membros superiores no decorrer da internação. 
Figura 5. Força muscular do membros superiores e inferiores avaliada pela escala do Medical Research Council

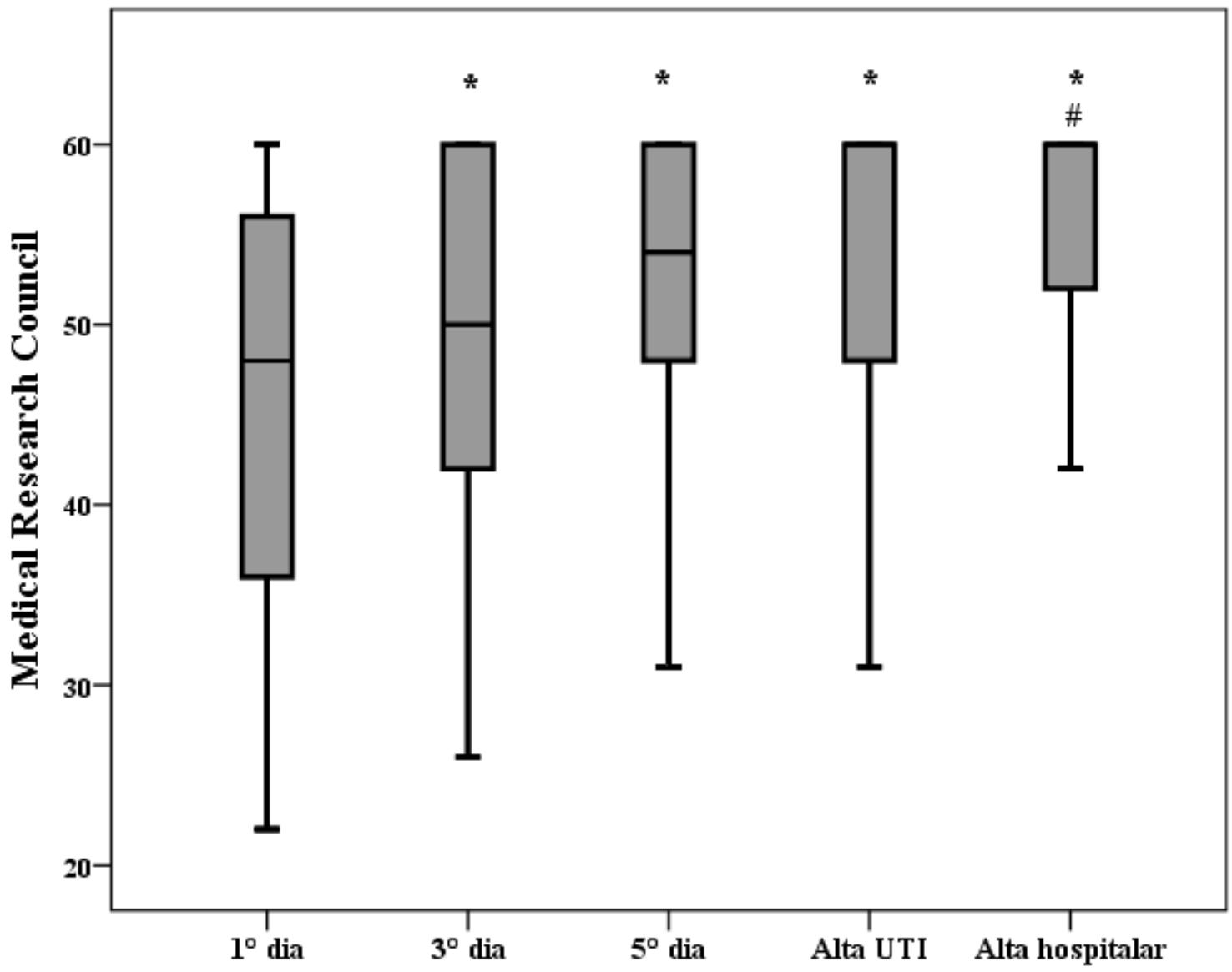

Legenda: Os valores apresentados representam a força muscular dos membros superiores e inferiores na avaliação do Medical Research Council. $\mathrm{O} 1^{\circ} \mathrm{dia}, 3^{\circ} \mathrm{dia}$ e 0 $5^{\circ}$ dia são os valores obtidos nos respectivos dias a partir do despertar. ${ }^{*} \mathrm{p}<0,05=$ comparação ao $1^{\circ} \mathrm{dia} ;{ }^{\&} \mathrm{p}<0,05=$ comparação ao $3^{\circ} \mathrm{dia}$. Para comparação da força muscular ao longo do tempo foi utilizada análise de variância de 1 fator com comparações multiplas de Bonferroni.

Em relação à força muscular dos membros superiores avaliada pela força de preensão palmar houve um aumento de 12,0 (7,0-20,0)Kgf do primeiro dia da avaliação para 19,0 (14,0-26,0)Kgf até a alta da UTI, com diferença significativa $(p<0,05)$ (figura 6$)$. Quando comparado com o esperado para altura, sexo e o índice de massa corpórea os pacientes apresentavam força de preenssão palmar em média de $42,1 \pm 21,9 \%$ do predito no $1^{\circ}$ dia de avaliação e este valor aumentou para $65,9 \pm 20,3 \%$ do predito no dia da alta hospitalar. 
Figura 6. Força muscular do membros superiores avaliada pela preensão palmar

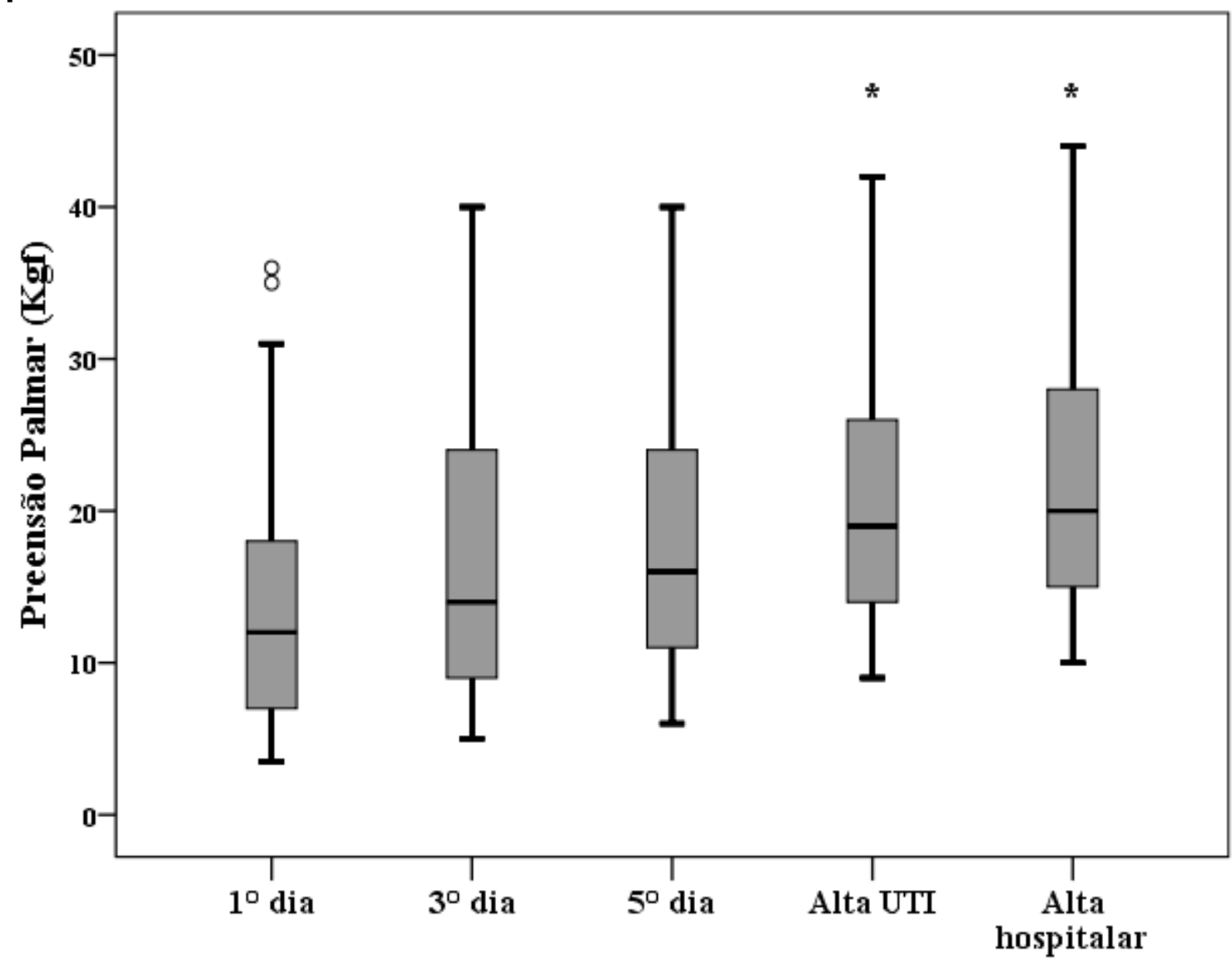

Legenda: Os valores apresentados representam a força muscular dos membros superiores através da força de preensão palmar. $O 1^{\circ}$ dia, $3^{\circ}$ dia e $05^{\circ}$ dia são os valores obtidos nos respectivos dias a partir do despertar. ${ }^{*} \mathrm{p}<0,05=$ comparação ao $1^{\circ}$ dia. Para comparação da força muscular ao longo do tempo foi utilizada análise de variância de 1 fator com comparações multiplas de Bonferroni.

No dia da alta da UTI houve uma correlação positiva moderada ( $r=0,56$; $p<0,05)$ entre área de secção transversa do reto femoral e a força de preensão palmar (figura 7). Esta associação se manteve significativa até a alta hospitalar com $r=0,57$ e $p<0,001$. Verificou-se uma associação entre força muscular pelo MRC com a área de secção transversa do reto femoral na alta da UTI, apresentando uma correlação significativa $(r=0,50 ; p=0,002)$. 
Figura 7. Correlação linear entre a área de secção transversa do reto femoral e a força de preensão palmar na alta da UTI

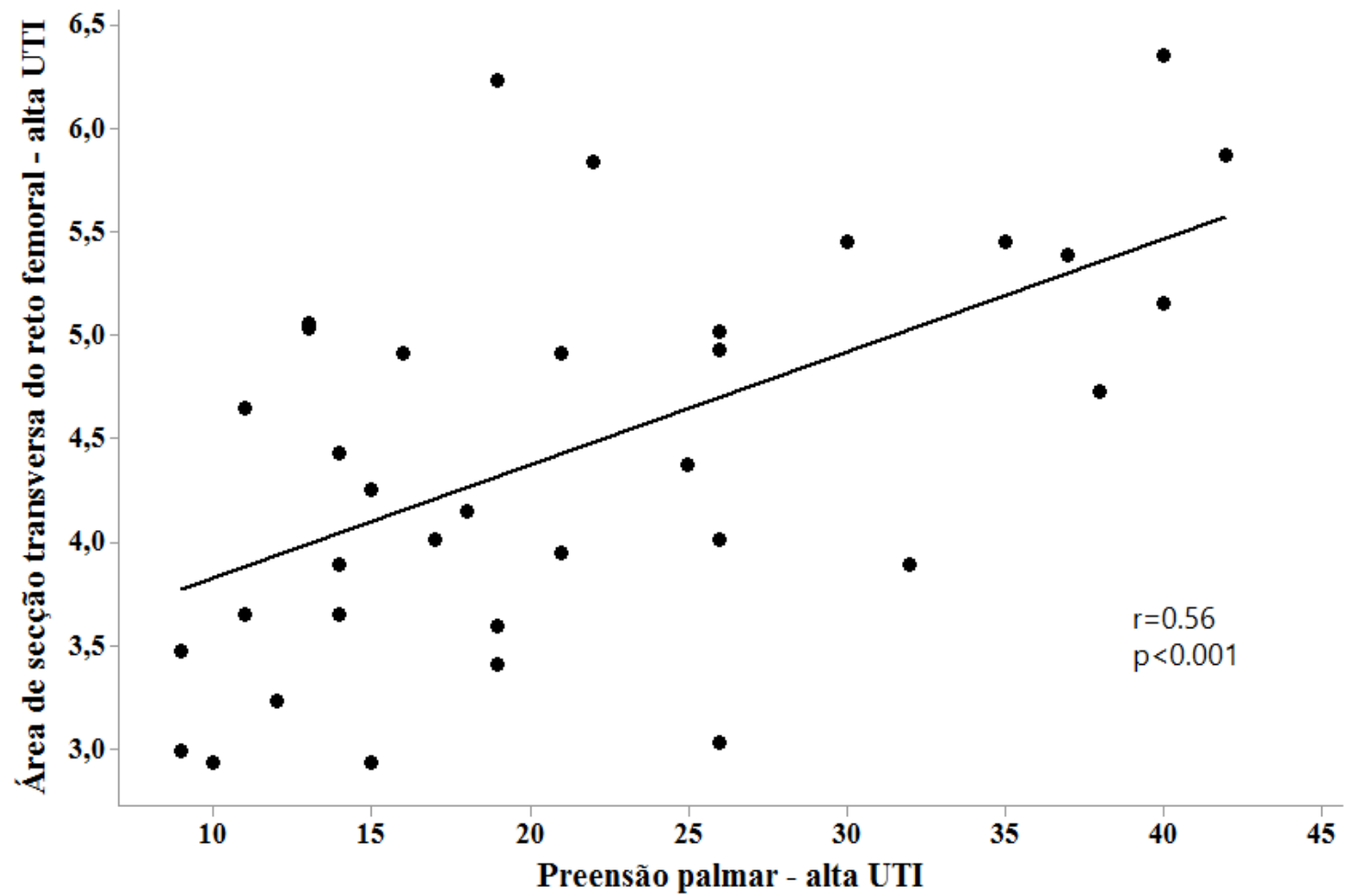

Legenda: Os valores apresentados representam os obtidos no dia da alta da uti na avaliação da área de secção transversa do reto femoral e na força de preensão palmar.

$\mathrm{Na}$ análise quantitativa da aldolase e da creatinoquinase, não houve alterações significativas $(p>0,05)$ nos períodos analisado do estudo, ver figura 8 e 9, respectivamente. Não houve associação da aldolase e da creatinoquinase com a força muscular ou a área de secção transversa do reto femoral em nenhum momento do estudo. 
Figura 8. Aldolase analisada dos pacientes durante a internação

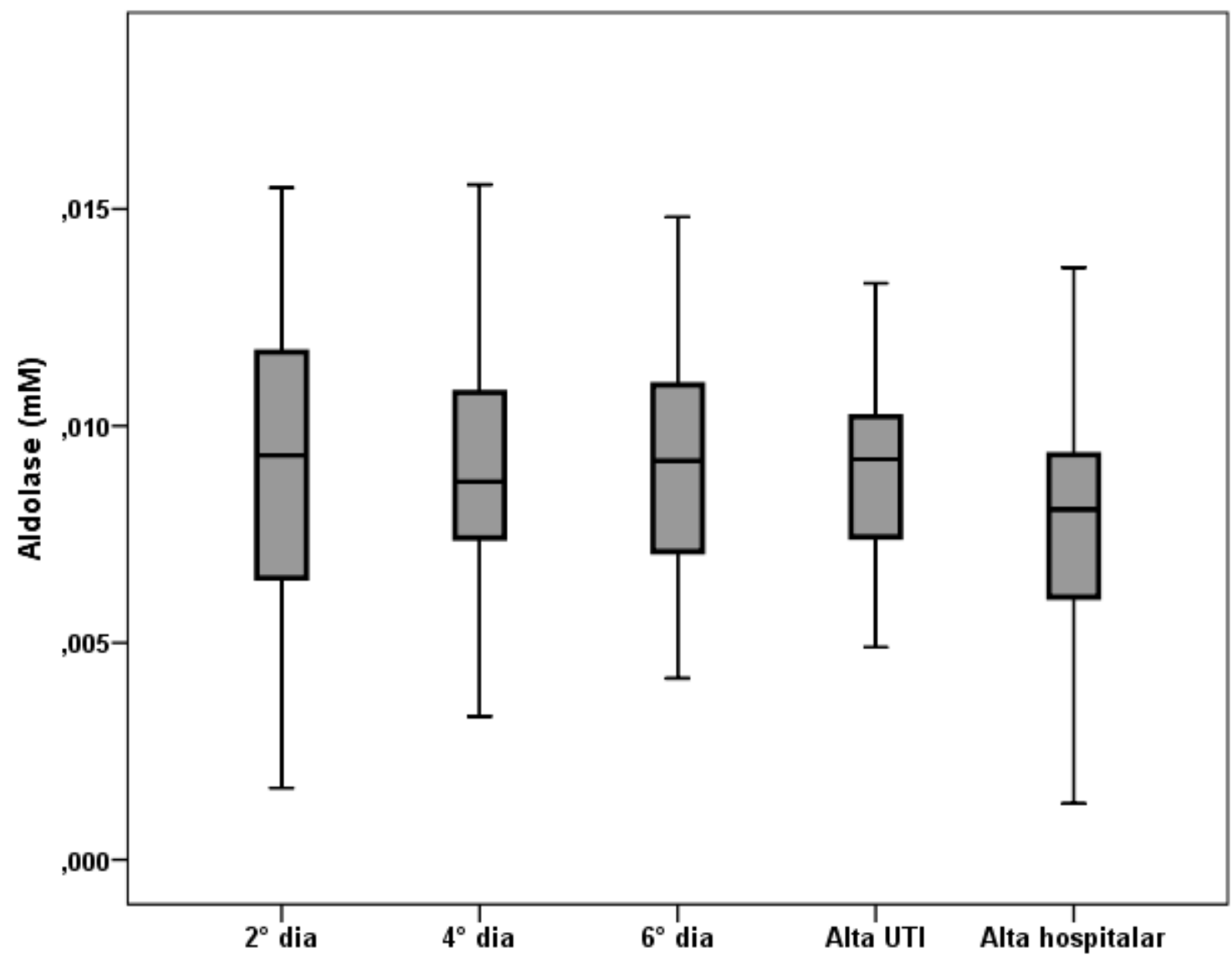

Legenda: Os valores apresentados representam os obtidos na quantificação da aldolase dos 37 pacientes do estudo. $O 2^{\circ}$ dia, $4^{\circ}$ dia, $6^{\circ}$ dia referem-se ao dia de internação na UTI. Não houve diferença significativa durante a internação $(p>0,05)$. Para comparação da aldolase ao longo do tempo foi utilizada análise de variância de 1 fator com comparações multiplas de Bonferroni. 
Figura 9. Creatinoquinase analisada dos pacientes durante a internação

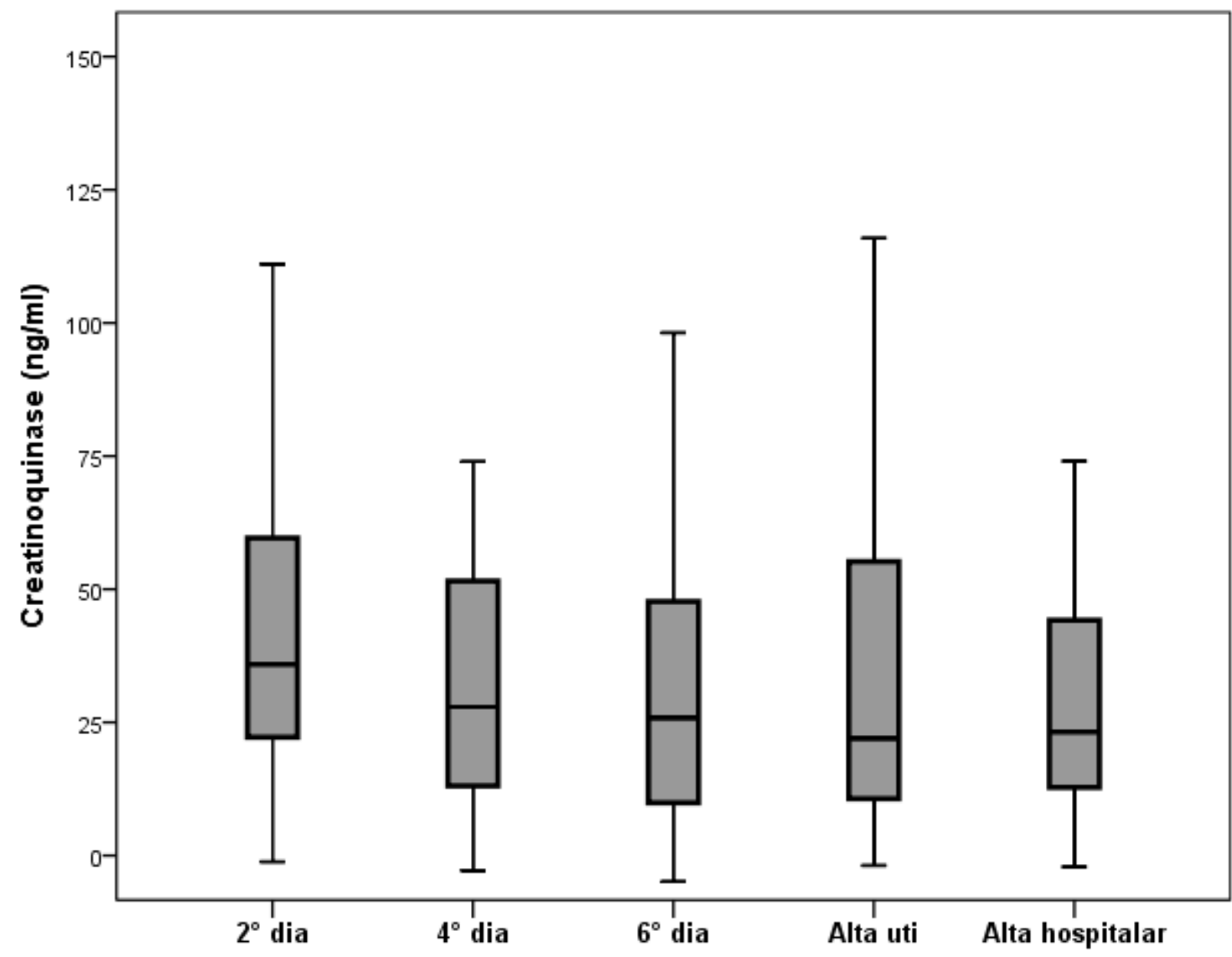

Legenda: Os valores apresentados representam os obtidos na quantificação da creatinoquinase dos 37 pacientes do estudo. $\mathrm{O} 2^{\circ}$ dia, $4^{\circ}$ dia, $6^{\circ}$ dia referem-se ao dia de internação na UTI. Não houve diferença significativa durante a internação $(p>0,05)$. Para comparação da creatinoquinase ao longo do tempo foi utilizada análise de variância de 1 fator com comparações multiplas de Bonferroni.

$\mathrm{Na}$ análise quantitativa da vitamina $\mathrm{D}$ houve um aumento significativo no dia da alta da UTI e da alta hospitalar em comparação ao $2^{\circ}$ dia de internação na UTI (figura 10). Houve uma associação positiva da vitamina D no $2^{\circ}$ dia de UTI e da força de preensão palmar na alta da UTI $(r=0,42 ; p<0,05)$ sem associção com a ASTrf no dia alta da UTI (r=0,24;p>0,05). 
Figura 10. Vitamina $D$ analisada dos pacientes durante a internação

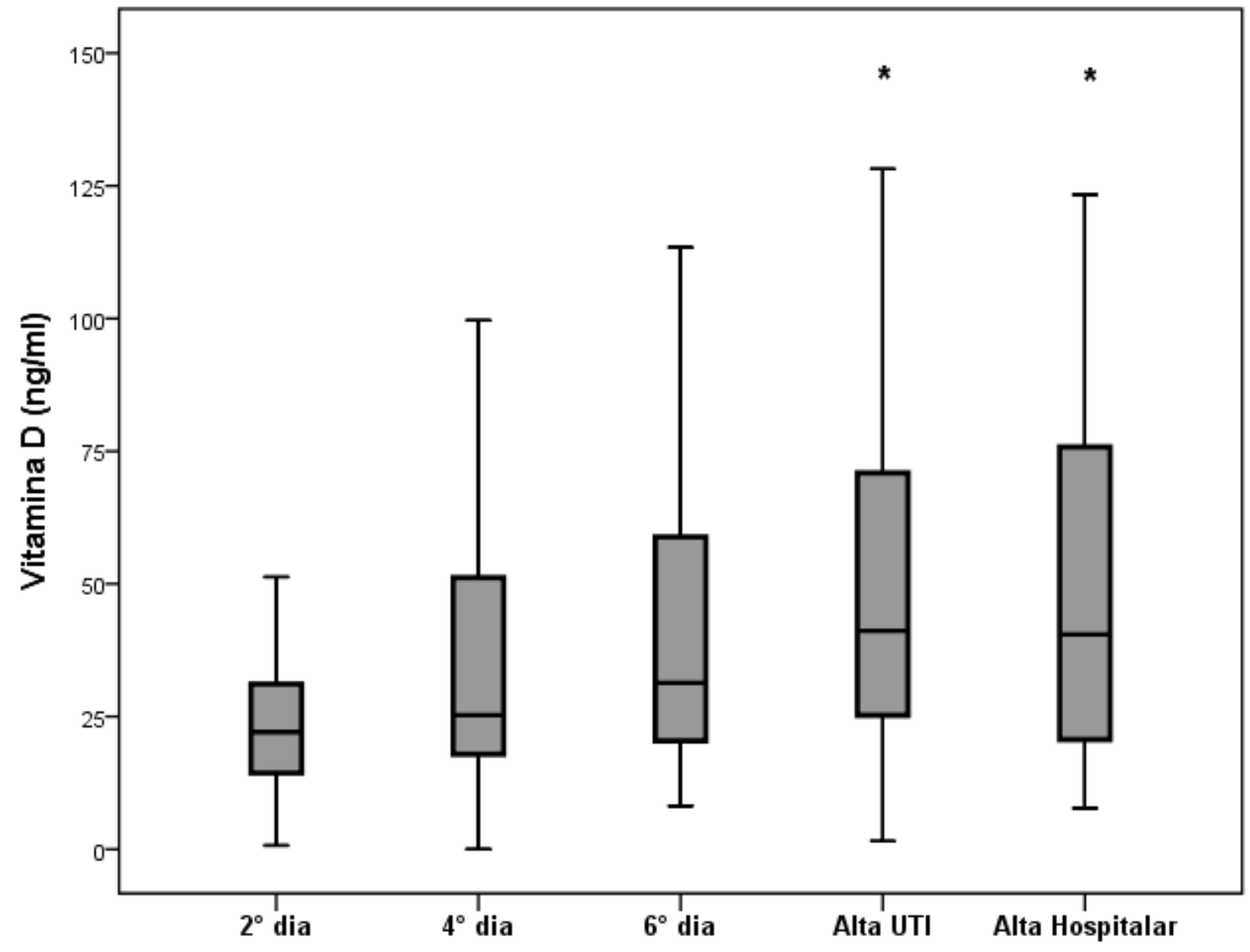

Legenda: Os valores apresentados representam os obtidos na quantificação da vitamina $D$ dos 37 pacientes do estudo. $O 2^{\circ}$ dia, $4^{\circ}$ dia, $6^{\circ}$ dia referem-se ao dia de internação na UTI. ${ }^{*} p<0,05$ em comparação ao $2^{\circ}$ dia de internação na UTI. Para comparação da vitamina $D$ ao longo do tempo foi utilizada análise de variância de 1 fator com comparações multiplas de Bonferroni.

As variáveis associadas $(p<0,05)$ na análise de regressão univariada ou na análise bivariada com o delta de variação $\left(2^{\circ}\right.$ dia - alta da UTI) da área de secção transversa do reto femoral ou com a força de preensão palmar (porcentagem do predito na alta da UTI) foram analisadas em um modelo de regressão multivariada (tabela 5). Houve uma associação independente do sexo e do escore SOFA do $3^{\circ}$ dia com o delta de variação da área de seção transversa entre $02^{\circ}$ dia e a alta da UTI, ou seja, pacientes do sexo masculino e um aumento do escore SOFA no $3^{\circ}$ dia tem uma chance maior de perda da 
área de secção transversa do reto femoral até a alta da UTI. Houve uma associação independente na análise de regressão multivariada do SOFA do $3^{\circ}$ dia com a porcentagem do predito na força de preensão palmar no dia da alta da UTI. 
Tabela 5 - Análise de regressão multivariada das variáveis clínicas analisadas durante o estudo

\begin{tabular}{|c|c|c|c|c|c|}
\hline Modelo & B & $\mathbf{T}$ & $\mathbf{p}$ & \multicolumn{2}{|c|}{$95 \%$ IC } \\
\hline \multicolumn{6}{|l|}{$\operatorname{ASTrf}\left(\Delta=2^{\circ}\right.$ dia $\left.-\operatorname{ICU}\right)$} \\
\hline Constante & 0,549 & 3,120 & 0,004 & 0,189 & 0,909 \\
\hline Gênero, feminino & $-0,337$ & $-2,371$ & $0,025^{*}$ & $-0,628$ & $-0,046$ \\
\hline Corticosteróides & 0,140 & 0,976 & 0,337 & $-0,154$ & 0,435 \\
\hline Ventilação mecânica & 0,151 & 0,916 & 0,367 & $-0,186$ & 0,488 \\
\hline SOFA, $3^{\circ}$ dia & 0,038 & 2,137 & $0,041^{*}$ & 0,002 & 0,075 \\
\hline Dias de UTI & 0,005 & 0,417 & 0,680 & $-0,018$ & 0,027 \\
\hline \multicolumn{6}{|c|}{ \% predito da força de preensão palmar (alta da UTI) } \\
\hline Constante & 75,434 & 4,690 & 0,000 & 42,536 & 108,332 \\
\hline Vitamina $D, 2^{\circ}$ dia & 0,136 & 1,515 & 0,141 & $-0,048$ & 0,320 \\
\hline Ventilação Mecânica & $-5,365$ & $-0,798$ & 0,432 & $-19,124$ & 8,394 \\
\hline SOFA, $3^{\circ}$ dia & $-2,267$ & $-2,862$ & $0,008^{*}$ & $-3,888$ & $-0,647$ \\
\hline SAPS3 & $-0,124$ & $-0,457$ & 0,651 & $-0,681$ & 0,433 \\
\hline Dias de UTI & 0,107 & 0,237 & 0,815 & $-0,816$ & 1,030 \\
\hline
\end{tabular}

ASTrf= Área de Secção Transversa do Reto Femoral; UTI= Unidade de Terapia Intensiva; SAPS 3=Simplified Acute Physiology Score 3; SOFA=Sequential Organ Failure Assessment; * $p<0.05$. 


\section{DISCUSSÃO}

Este estudo demonstrou que os pacientes transferidos para UTI por sepse grave ou choque séptico tem degradação muscular em curto prazo, independentemente de terem sido ou não submetidos à ventilação mecânica. A força muscular manteve-se com valores abaixo do previsto até o dia da alta hospitalar, apesar dos pacientes apresentarem uma recuperação gradual durante a internação. Houve uma associação da massa muscular e das avaliações clínicas de força muscular durante a permanência na UTI. Por último, um escore elevado de lesão orgânica no $3^{\circ}$ dia e ser do sexo masculino apresentam uma associação maior para o declínio da ASTrf, assim como, do SOFA do $3^{\circ}$ dia com a fraqueza muscular.

Os resultados demonstraram que os pacientes sépticos apresentaram uma taxa média de degradação muscular de $1,5 \%$ ao dia durante a permanência na UTI, sendo mais evidente nos pacientes em ventilação mecânica quando comparado a aqueles sem ventilação mecânica $(1,75 \%$ x $1,0 \%$ ao dia). Estes valores de degradação estão próximos aos obtidos por outros autores $^{18}$ na qual observaram um declínio de 1,6\% (variação de 0,2$5,7 \%$ ) ao dia em 48 pacientes críticos. Puthucheary et al. ${ }^{74}$ em 2013, publicou um estudo sobre degradação muscular em pacientes críticos submetidos a ventilação mecânica por mais de 48 horas e encontraram uma redução significativa do dia 1 para o dia $7(-12,5 \% ; p=0,002)$ e que continuou a cair até o dia 10 (-17,7\%; $p<0,001)$. Em pacientes com falência de múltiplos órgãos, foi identificada uma taxa de degradação muscular muito maior chegando até $6 \%$ ao $\mathrm{dia}^{28}$. Nos pacientes sépticos, um estudo transversal demonstrou valores 
próximos a $58 \%$ dos obtidos em indivíduos saudáveis ${ }^{62}$. Em nosso estudo, não houve nenhuma restrição a inclusão dos pacientes em relação à ventilação mecânica, contrastando com a literatura que incluiu somente pacientes submetidos à ventilação mecânica ${ }^{18,74}$. Esta diferença de abordagem poderia subestimar a taxa de degradação muscular em comparação aos demais estudos, contudo isto não aconteceu. Este racional vem de modelos animais $^{75,76}$ que permitiram separar a sepse de outros fatores de risco, por exemplo, ventilação mecânica e a ausência de contração muscular. Nestes estudos não foi possível demonstrar atrofia muscular na ausência de ventilação mecânica. No entanto, em humanos a degradação pode ocorrer pela ampla variedade de condições ligadas a UTI como o imobilismo, hiperglicemia, o uso de corticosteróides e outros fatores contribuintes a atrofia muscular. Conforme demonstrado em outros estudos, a presença e a persistência da sepse tem um papel central em ocasionar a degradação muscular ${ }^{72,77}$.

O exato mecanismo da perda de massa muscular permanece desconhecido ${ }^{19,20,22}$. Estudos que examinaram as alterações na composição e na massa corpórea nestes pacientes observaram uma perda de massa magra e de proteínas ${ }^{19,20,22}$. A musculatura esquelética é considerada um reservatório de proteínas que podem ser alvo de proteólise e atrofia, principalmente, das fibras do tipo $\mathrm{II}^{78}$. Streat et al. ${ }^{19}$ identificaram uma perda significativa de $12,5 \%$ da quantidade de proteína corporal total em pacientes com choque séptico. Isto também foi observado por outros autores onde houve uma redução de $13 \%$ da quantidade de proteínas em apenas três semanas ${ }^{79}$. Em pacientes críticos a síntese de proteínas musculares pode ser suprimida a níveis equivalentes a estados de jejum no primeiro dia da doença. Posteriormente se elevando, mas 
mantendo um estado de catabolismo muscular durante a permanência na UTI, independente do suporte nutricional e farmacológico oferecido ${ }^{74}$.

\subsection{Aferição da área de secção transversa do reto femoral}

A escolha do músculo reto femoral para avaliação da degradação muscular foi feita porque ele é: 1) um músculo facilmente acessível ${ }^{63}$; 2) utilizado em estudos de ultrassonografia dentro do ambiente de terapia intensiva $^{61}$ e 3) correlacionou-se bem com as avaliações clínicas de força muscular em outras populações ${ }^{63}$. Ele é um dos quatro músculos que compõem o músculo quadríceps junto com o vasto lateral, vasto intermédio e o vasto medial. O reto femoral tem sido utilizado há alguns anos como uma representação do quadríceps em estudos de imagem da musculatura esquelética em humanos ${ }^{61,63,74,80}$. No entanto, a ASTrf constitui apenas $10 \%$ da área de secção transversa total do músculo quadríceps ${ }^{81}$. Apesar de representar somente uma pequena parte do músculo quadríceps total, os demais músculos do quadríceps podem sofrer degradação muscular de forma similar as observadas no reto femoral. De fato, isto foi observado em estudos sobre perdas musculares relacionadas ao envelhecimento ${ }^{81}$, onde a proporção da área de secção transversa do reto femoral em relação ao quadríceps total foi semelhante entre jovens e idosos de ambos os sexos. Por isso, optamos por utilizar o reto femoral para representar as modificações sofridas pela musculatura esquelética dos membros inferiores durante a fase crítica da doença. 


\subsection{Fraqueza muscular na sepse}

A sepse leva a degradação muscular e também uma perda da força muscular. No primeiro dia da avaliação da força muscular os pacientes apresentavam valores próximos a $42 \%$ do previsto na força de preensão palmar. Eikermann et al. ${ }^{34}$ encontraram uma redução em torno de $30 \%$ da força muscular esquelética em pacientes sépticos em comparação a controles. Outros autores demonstraram ainda, através de medidas eletrofisiológicas, uma fraqueza distal dos membros ${ }^{38}$. Esta fraqueza também pode ser verificada com a escala do $M R C$, onde $25 \%$ dos atuais pacientes apresentavam sinais de fraqueza muscular $(M R C<48)$ no dia da alta da UTI. Estes valores são similares $(25,3 \%)$ aos obtidos em um estudo sobre fraqueza muscular adquirida na $\mathrm{UTT}^{72}$. Estes dados são preocupantes porque uma pontuação $<48$ está associada a piores resultados clínicos, sendo considerada um preditor independente de desmame prolongado, dias de UTI e de internação hospitalar ${ }^{17,82}$.

A fraqueza muscular pode ser transitória ou permanente. No estudo, os pacientes apresentaram uma recuperação gradual da força de preensão palmar com valores iniciando em $42,1 \%$ do predito chegando a quase $60 \%$ do predito ao final da hospitalização. Esta recuperação gradual da força foi observada anteriormente em pacientes sépticos do momento da alta hospitalar até 3 meses após a internação ${ }^{83}$. Em pacientes críticos, a fraqueza muscular apresentou uma recuperação dentro de 12 meses $^{84}$. Por outro lado, naqueles com fraqueza acima deste período, foi observado um declínio substancial da função física e da saúde relacionada à qualidade de vida ${ }^{84}$. As causas para estas disfunções musculares a curto e longo prazo têm sido atribuídas a 
diversos fatores que vão desde a diminuição da excitabilidade da membrana, lesão da membrana sarcolemal, alteração da homeostase do cálcio, aumento da degradação proteica, redução da síntese proteica e a inflamação sistêmica $^{46}$. Independentemente da causa, estes resultados trazem informações prognósticas a respeito da recuperação física após a sepse e, permite um direcionamento para novos estudos sobre reabilitação precoce ou pós-internação em melhorar as complicações físicas provocadas pela sepse.

Durante o estudo houve uma recuperação da força muscular e um declínio da ASTrf. É importante realçar que a avaliação da força muscular começou a ser realizada a partir do despertar dos pacientes, diferentemente da ASTrf, que ocorreu já no $2^{\circ}$ dia de internação na UTI. Desta forma, as avaliações podem ter ocorrido em fases distintas da doença, isto é, a ASTrf abrangendo todo o período de internação e a medida de força do despertar até a alta hospitalar. As alterações da força e da degradação evoluíram de formas distintas. É importante entender que a força muscular é dependente de dois fatores: força muscular gerada por uma quantidade de massa muscular e a massa muscular total. Estes fatores representam dois aspectos distintos da função muscular e podem alterar a força muscular independentemente uma da outra. A degradação muscular pode ocorrer sem produzir mudanças na geração de força específica do músculo. Por exemplo, em um modelo de privação nutricional prolongada, Lewis et al. ${ }^{85}$ demonstraram que a massa total do diafragma foi reduzida em $50 \%$, mas a força específica do diafragma a geração permaneceu normal. Além disso, Le Bourdelles et al. ${ }^{86}$ demonstraram que após 48 horas de ventilação mecânica, a massa muscular dos membros reduziu-se significativamente sem reduções concomitantes na geração de força 
específica do músculo do membro. Portanto, embora reduções de força e perda de massa muscular possam ocorram simultaneamente, é importante entender que as reduções na geração de força específica de músculo podem existir na ausência de atrofia e a atrofia pode ocorrer sem reduzir a geração de força específica do músculo. Do mesmo modo, o aumento da massa muscular não necessariamente melhora a geração de força específica do músculo, como demonstrado em estudos experimentais ${ }^{87}$.

\subsection{Fatores associados à degradação muscular}

Aumentos no escore de lesão orgânica (SOFA) no $3^{\circ}$ dia e o sexo demonstraram serem fatores de risco para um declínio mais acentuado da ASTrf. Em um recente estudo estes achados também foram observados entre lesão orgânica e as alterações no reto femoral ${ }^{74}$. A literatura relata que os pacientes com lesão em mais de um órgão tiveram um declínio mais acentuado da ASTrf quando comparado a pacientes com lesão em um único órgão no dia $3(-8,7 \%$ vs $-1,8 \% ; p=0.03)$ e no dia $7(-15,7 \%$ vs $-3.0 \% ; p<0,001)$, respectivamente. Além disso, as alterações também foram maiores naqueles com 4 ou mais lesões orgânicas do que naqueles com 2 ou 3 lesões orgânicas $(-20,3 \% \text { vs }-13,9 \% ; p<0,001)^{74}$. Conforme demonstrado anteriormente, é possível que os pacientes com falência de múltiplos órgãos experimentem maiores distúrbios fisiológicos envolvidos na patogênese da degradação muscular $^{88}$. Outro fator de risco apontado em nosso estudo para o declínio da ASTrf foi o sexo masculino. Estes achados podem ser justificados pelos resultados apresentados anteriormente por Reid et al. ${ }^{18}$, no qual os pacientes com maior massa muscular perderam em um ritmo mais rápido do que os 
demais. Em geral, os pacientes do sexo masculino apresentam maior massa muscular em comparação às mulheres. É impossível saber, se as pacientes do sexo feminino em nosso estudo tinham perdido massa muscular antes da admissão no estudo. Dados a partir de biópsias musculares em série sugerem uma perda mais acentuada nos primeiros dias ${ }^{25}$, no entanto, a inclusão dos pacientes em nosso estudo ocorreu de forma semelhante em ambos os sexos o que não justificaria essa afirmação.

\subsection{Aferições clínicas da força muscular e suas associações}

Atualmente tem sido discutida a capacidade dos testes, dinamometria e a escala do MRC, em avaliar a força muscular dentro do ambiente de UTI ${ }^{89}$. Isto ocorre pela necessidade de esforços máximos dos pacientes e pela incapacidade de cooperação na fase inicial da doença devido às condições clínicas e ao tratamento medicamentoso. No estudo, optou-se por realizar os testes nos pacientes a partir da estabilização clínica e em condições de cooperar. Estas estratégias foram utilizadas em outros estudos com sucesso durante a avaliação da força muscular em UTI ${ }^{58,72}$. Em nosso estudo um paciente não conseguiu realizar a avaliação da força pela escala do $M R C$ e a dinamometria nos cinco momentos das avaliações por alteração do nível de consciência. Isto representou menos de $3 \%$ do total das avalições. Desta forma, estes testes mostram-se factíveis e capazes de serem aplicados

rotineiramente no ambiente hospitalar pelo tempo e praticidade em sua realização.

As medidas da ASTrf podem ser utilizadas como uma ferramenta de avaliação indireta da força muscular em pacientes sépticos mesmo durante 
estados de inconsciência e de instabilidade clínica. No estudo, a ASTrf correlacionou-se com as avaliações clínicas de força muscular na alta da UTI. Em outras populações a ASTrf foi significativamente correlacionada com a força de contração isométrica voluntária máxima em indivíduos saudáveis $(r=0,80, p<0,001)$ e pessoas com doença pulmonar obstrutiva crônica $(r=0,78$, $p<0,001)^{63}$. Em pacientes sépticos foi demonstrada uma associação da espessura muscular com a força muscular dos membros superiores ${ }^{62}$. Além disso, outro exame de imagem, a tomografia, também demonstrou uma associação entre a massa e a força muscular ${ }^{90}$. Desta forma, a avaliação da ASTrf feita pelo ultrassom pode nortear estratégias para combater a perda de massa muscular e a fraqueza provocada pela sepse desde os estágios iniciais da doença.

\subsection{Marcadores bioquímicos}

Em nosso estudo houve uma correlação positiva da vitamina $D$ com a força muscular no dia da alta da UTI. A vitamina D é um hormônio que tem um papel chave sobre o cálcio, o balanço do fosfato e nas estruturas ósseas ${ }^{91,92}$. Outras funções da vitamina D ocorrem na musculatura esquelética envolvendo o transporte de cálcio e a síntese protéica ${ }^{93,94}$. A deficiência de vitamina $D$ tem sido relacionada à diminuição da força e da massa muscular ${ }^{95,96}$, com prejuízo do equilíbrio e aumento da incidência de quedas ${ }^{97}$. Visser et al. $^{96}$ demonstraram uma diminuição da força e da massa muscular apendicular em pacientes com níveis séricos menores do que $25 \mathrm{nmol} / \mathrm{L}$. Dhanwal et $\mathrm{al}^{98}$ também observou uma correlação positiva da vitamina $D$ com a força de preensão palmar, semelhante aos nossos resultados. Atualmente, alguns 
estudos tem utilizado a suplementação de vitamina $D$ a médio e longo prazo com o intuito de melhorar a força muscular e resultados favoráveis têm sido obtidos $^{99,100}$. No entanto, pouco se sabe sobre seus efeitos em curto prazo na força muscular em pacientes sépticos internados em UTI.

A creatinoquinase e a aldolase não se alteraram de forma significativa durante a internação e não apresentaram associação com a massa ou a força muscular. Estas enzimas tem papel na produção de energia para o metabolismo muscular e aumentam seus níveis na presença de lesão muscular em alguns estados patológicos ${ }^{101,102}$. Estudos com biópsias têm demonstrado degeneração axonal de fibras sensitivas e motoras e necrose de fibras musculares em pacientes com fraqueza muscular adquirida na $\mathrm{UTI}^{103}$ e, mesmo assim, a creatinoquinase e a aldolase não foram capazes de detectar lesão muscular no estudo. Anteriormente, níveis normais de creatinoquinase ou ausência de alterações no decorrer do tempo foram observados em pacientes com processos miopáticos desenvolvidos durante a permanência na UTI ${ }^{104,105}$. Portanto, a sensibilidade destas enzimas em detectar lesão muscular em pacientes de UTI pode ser limitada.

Este estudo tem algumas limitações. Primeiro, os testes de força de preensão palmar e a escala do $M R C$ utilizados no estudo são dependentes da motivação do paciente, limitação pertinente a todo estudo que avalie força muscular em pacientes críticos. No entanto, tentamos minimizar estes efeitos considerando aptos a realizar o teste somente os pacientes que passaram na avaliação diária do despertar. Segundo: devido à gravidade e a velocidade de instalação da doença nós não podíamos obter as mensurações de força muscular e da ASTrf antes da entrada na UTI e assim determinar a magnitude 
das alterações provocadas pela sepse. No entanto, usamos dados normativos para população em geral no teste de força de preensão palmar. Terceiro: não conseguimos avaliar os efeitos das intervenções físicas realizadas durante 0 período intra-hospitalar sobre o processo de recuperação destes pacientes. Quarto: os nossos resultados não podem ser generalizados para toda população sobrevivente de UTI, somente para aqueles encaminhados por sepse grave ou choque séptico. 


\section{CONCLUSÕES}

Os resultados do presente estudo permitem concluir: 1) Os pacientes sépticos encaminhados a UTI apresentaram uma morbidade física substancial até a alta hospitalar, demonstrada pelo declínio da área de secção transversa do reto femoral; 2) Durante a internação houve uma recuperação da força muscular nos pacientes sobreviventes de sepse, mas ainda com valores abaixo do esperado; 3) Houve associação entre a degradação muscular e os testes clínicos de força e 4) O escore de lesão orgânica associou-se com a degradação muscular e a fraqueza muscular, assim como o sexo sobre a degradação muscular nos sobreviventes de sepse. 


\section{ANEXO}

\section{Anexo 1. Escore de lesão orgânica SOFA}

Table 3 The SOFA score

\begin{tabular}{|c|c|c|c|c|}
\hline SOFA score & 1 & 2 & 3 & 4 \\
\hline $\begin{array}{l}\text { Respiration } \\
\mathrm{PaO}_{2} / \mathrm{FiO}_{2}, \mathrm{mmHg}\end{array}$ & $<400$ & $<300$ & $<200$ & $\begin{array}{l}<100 \\
\text { pport }-\end{array}$ \\
\hline $\begin{array}{l}\text { Coagulation } \\
\text { Platelets } \times 10^{3} / \mathrm{mm}^{3}\end{array}$ & $<150$ & $<100$ & $<50$ & $<20$ \\
\hline $\begin{array}{l}\text { Liver } \\
\text { Bilirubin, } \mathrm{mg} / \mathrm{dl} \\
(\text { mol/l) }\end{array}$ & $\begin{array}{l}1.2-1.9 \\
(20-32)\end{array}$ & $\begin{array}{l}2.0-5.9 \\
(33-101)\end{array}$ & $\begin{array}{l}6.0-11.9 \\
(102-204)\end{array}$ & $\begin{array}{l}>12.0 \\
(<204)\end{array}$ \\
\hline $\begin{array}{l}\text { Cardiovascular } \\
\text { Hypotension }\end{array}$ & $\mathrm{MAP}<70 \mathrm{mmHg}$ & $\begin{array}{l}\text { Dopamine } \leq S \\
\text { or dobutamine (any dose) }\end{array}$ & $\begin{array}{l}\text { Dopamine }>5 \\
\text { or epinephrine } \leq 0.1 \\
\text { or notepinephrine } \leq 0.1\end{array}$ & $\begin{array}{l}\text { Dopamine }>15 \\
\text { or epinephrine }>0.1 \\
\text { or norepinephrine }>0.1\end{array}$ \\
\hline $\begin{array}{l}\text { Central nervous system } \\
\text { Glasgow Coma Score }\end{array}$ & $13-14$ & $10-12$ & $6-9$ & $<6$ \\
\hline $\begin{array}{l}\text { Renal } \\
\text { Creatinine, mg/dl } \\
(\mu \mathrm{mol} / \mathrm{l}) \text { or urine } \\
\text { output }\end{array}$ & $\begin{array}{l}1.2-1.9 \\
(110-170)\end{array}$ & $\begin{array}{l}2.0-3.4 \\
(171-299)\end{array}$ & $\begin{array}{l}3.5-4.9 \\
(300-440) \\
\text { or }<500 \mathrm{ml} / \text { day }\end{array}$ & $\begin{array}{l}>5.0 \\
(>440) \\
\text { or }<200 \mathrm{ml} / \text { day }\end{array}$ \\
\hline
\end{tabular}

"Adrenergic agents administered for at least $1 \mathrm{~h}$ (doses given are in $\mu \mathrm{g} / \mathrm{kg} \cdot \mathrm{min}$ ) 


\section{REFERÊNCIAS BIBLIOGRÁFICAS}

1. Singer M, Deutschman CS, Seymour CW, Shankar-Hari M, Annane D, Bauer M, Bellomo R, Bernard GR, Chiche JD, Coopersmith CM, Hotchkiss RS, Levy MM, Marshall JC, Martin GS, Opal SM, Rubenfeld GD, van der Poll T, Vincent JL, Angus DC.The Third International Consensus Definitions for Sepsis and Septic Shock (Sepsis-3). JAMA. 2016 Feb 23;315(8):801-10.

2. Shankar-Hari M, Phillips GS, Levy ML, Seymour CW, Liu VX, Deutschman CS, Angus DC, Rubenfeld GD, Singer M; Sepsis Definitions Task Force. Developing a New Definition and Assessing New Clinical Criteria for Septic Shock: For the Third International Consensus Definitions for Sepsis and Septic Shock (Sepsis-3). JAMA. 2016 Feb 23;315(8):775-87.

3. Martin GS, Mannino DM, Eaton S, Moss M. The epidemiology of sepsis in the United States from 1979 through 2000. N Engl J Med. 2003 Apr $17 ; 348(16): 1546-54$.

4. Silva E, Pedro Mde A, Sogayar AC, Mohovic T, Silva CL, Janiszewski M, Cal RG, de Sousa EF, Abe TP, de Andrade J, de Matos JD, Rezende E, Assunção M, Avezum A, Rocha PC, de Matos GF, Bento AM, Corrêa AD, Vieira PC, Knobel E; Brazilian Sepsis Epidemiological Study. Brazilian Sepsis Epidemiological Study (BASES study). Crit Care. 2004 Aug;8(4):R251-60.

5. Sogayar AM, Machado FR, Rea-Neto A, Dornas A, Grion CM, Lobo SM, Tura BR, Silva CL, Cal RG, Beer I, Michels V, Safi J, Kayath M, Silva E; Costs Study Group - Latin American Sepsis Institute. A multicentre, prospective study to evaluate costs of septic patients in Brazilian intensive care units. Pharmacoeconomics. 2008;26(5):425-34. 
6. O'Brien JM Jr, Ali NA, Aberegg SK, Abraham E. Sepsis. Am J Med. 2007 Dec;120(12):1012-22.

7. Hirschtick RE, Glassroth J, Jordan MC, Wilcosky TC, Wallace JM, Kvale PA, Markowitz N, Rosen MJ, Mangura BT, Hopewell PC. Bacterial pneumonia in persons infected with the human immunodeficiency virus. Pulmonary Complications of HIV Infection Study Group. N Engl J Med. 1995 Sep 28;333(13):845-51.

8. Williams MD, Braun LA, Cooper LM, Johnston J, Weiss RV, Qualy RL, LindeZwirble W. Hospitalized cancer patients with severe sepsis: analysis of incidence, mortality, and associated costs of care. Crit Care. 2004 Oct;8(5):R291-8.

9. Foreman MG, Mannino DM, Moss M. Cirrhosis as a risk factor for sepsis and death: analysis of the National Hospital Discharge Survey. Chest. 2003 Sep;124(3):1016-20.

10. O'Brien JM Jr, Lu B, Ali NA, Martin GS, Aberegg SK, Marsh CB, Lemeshow S, Douglas IS. Alcohol dependence is independently associated with sepsis, septic shock, and hospital mortality among adult intensive care unit patients. Crit Care Med. 2007 Feb;35(2):345-50.

11. Lundberg JS, Perl TM, Wiblin T, Costigan MD, Dawson J, Nettleman MD, Wenzel RP. Septic shock: an analysis of outcomes for patients with onset on hospital wards versus intensive care units. Crit Care Med. 1998 Jun;26(6):10204.

12. Dellinger RP, Carlet JM, Masur H, Gerlach H, Calandra T, Cohen J, GeaBanacloche J, Keh D, Marshall JC, Parker MM, Ramsay G, Zimmerman JL, Vincent JL, Levy MM; Surviving Sepsis Campaign Management Guidelines 
Committee. Surviving Sepsis Campaign guidelines for management of severe sepsis and septic shock. Crit Care Med. 2004 Mar;32(3):858-73.

13. Rivers E, Nguyen B, Havstad S, Ressler J, Muzzin A, Knoblich B, Peterson E, Tomlanovich M; Early Goal-Directed Therapy Collaborative Group. Early goal-directed therapy in the treatment of severe sepsis and septic shock. N Engl J Med. 2001 Nov 8;345(19):1368-77.

14. Bosscha K, Reijnders K, Jacobs MH, Post MW, Algra A, van der Werken C. Quality of life after severe bacterial peritonitis and infected necrotizing pancreatitis treated with open management of the abdomen and planned reoperations. Crit Care Med. 2001 Aug;29(8):1539-43.

15. Heyland DK, Hopman W, Coo H, Tranmer J, McColl MA. Long-term healthrelated quality of life in survivors of sepsis. Short Form 36: a valid and reliable measure of health-related quality of life. Crit Care Med. 2000 Nov;28(11):3599605.

16. Perl TM, Dvorak L, Hwang T, Wenzel RP. Long-term survival and function after suspected gram-negative sepsis. JAMA. 1995 Jul 26;274(4):338-45.

17. De Jonghe B, Bastuji-Garin S, Durand MC, Malissin I, Rodrigues P, Cerf C, Outin H, Sharshar T; Groupe de Réflexion et d'Etude des Neuromyopathies en Réanimation. Respiratory weakness is associated with limb weakness and delayed weaning in critical illness. Crit Care Med. 2007 Sep;35(9):2007-15.

18. Reid CL, Campbell IT, Little RA. Muscle wasting and energy balance in critical illness. Clin Nutr. 2004 Apr;23(2):273-80.

19. Streat SJ, Beddoe AH, Hill GL. Aggressive nutritional support does not prevent protein losses despite fat gain in septic intensive care patients. $J$ Trauma.1987;27(3):262-6. 
20. Green CJ, Campbell IT, McClelland P, Hutton JL, Ahmed MM, Helliwell TR, Wilkes RG, Gilbertson AA, Bone JM. Energy and nitrogen balance and change in midupper-arm circumference with multiple organ failure. Nutrition. 1995;11(6):739-46.

21. Hart DW, Wolf SE, Herndon DN, Chinkes DL, Lal SO, Obeng MK, Beauford RB, Mlcak RT RP. Energy expenditure and caloric balance after burn. Increased feeding leads to fat rather than lean mass accretion. Ann Surg. 2002 Jan;235(1):152-61.

22. Plank LD, Hill GL. Similarity of changes in body composition in intensive care patients following severe sepsis or major blunt injury. Ann N Y Acad Sci. 2000;904:592-602.

23. Manning EMC, Shenkin A. Nutritional assessment in the critically ill. Crit Care Clin. 1995;11:603-34.

24. Hill GL. Implications of critical illness, injury and sepsis on lean body mass and nutritional needs. Nutrition. 1998; 14:557-8.

25. Helliwell TR, Coakley JH, Wagenmakers AJ, Griffiths RD, Campbell IT, Green CJ, McClelland P, Bone JM. Necrotising myopathy in critically ill patients. J Pathol. 1991 Aug;164(4):307-14.

26. Helliwell TR, Wilkinson A, Griffiths RD, McClelland P, Palmer TE, Bone JM. Muscle fibre atrophy in critically ill patients is associated with the loss of myosin filaments and the presence of lysosomal enzymes and ubiquitin. Neuropathol Appl Neurobiol.1998;24:507-17.

27. Griffiths RD, Palmer TE, Helliwell T, MacLennan P, MacMillan RR. Effect of passive stretching on the wasting of muscle in the critically ill. Nutrition. 1995;11:428-32. 
28. Campbell IT, Watt T, Withers D, England R, Sukumar S, Keegan MA, Faragher B, Martin DF. Muscle thickness, measured with ultrasound may be an indicator of lean tissue wasting in multiple organ failure in the presence of edema. Am J Clin Nutr. 1995 Sep;62(3):533-9.

29. Walton JM, Roberts N, Whitehouse GH. Measurement of the quadriceps femoris muscle using magnetic resonance and ultrasound imaging. Br J Sports Med. 1997; 31: 59-64.

30. Dupont AC, Sauerbrei EE, Fenton PV, Shragge PC, Loeb GE, Richmond FJ. Real-time sonography to estimate muscle thickness: comparison with MRI and CT. J Clin Ultrasound. 2001;29:230-236.

31. Hussain SNA. Repiratory muscle dysfunction in sepsis. Mol Cell Biochem. 1998 Feb;179(1-2):125-34.

32. Latronico N, Rasulo FA, Recupero D, Beindorf A, Liberini P, Stefini R, Candiani A. Acute quadriplegia with delayed onset and rapid recovery. Case report. J Neurosurg. 1998 Apr;88(4):769-72.

33. Man WD, Moxham J, Polkey MI. Magnetic stimulation for the measurement of respiratory and skeletal muscle function. Eur Respir J. 2004 Nov;24(5):84660.

34. Eikermann M, Koch G, Gerwig M, Ochterbeck C, Beiderlinden M, Koeppen S, Neuhäuser M, Peters J. Muscle force and fatigue in patients with sepsis and multiorgan failure. Intensive Care Med. 2006 Feb;32(2):251-9.

35. Watson AC, Hughes PD, Louise Harris M, Hart N, Ware RJ, Wendon J, Green M, Moxham J. Measurement of twitch transdiaphragmatic, esophageal, and endotracheal tube pressure with bilateral anterolateral magnetic phrenic 
nerve stimulation in patients in the intensive care unit. Crit Care Med. 2001 Jul;29(7):1325-31.

36. Harris ML, Luo YM, Watson AC, Rafferty GF, Polkey MI, Green M, Moxham J. Adductor pollicis twitch tension assessed by magnetic stimulation of the ulnar nerve. Am J Respir Crit Care Med. 2000 Jul;162(1):240-5.

37. Swallow EB, Gosker HR, Ward KA, Moore AJ, Dayer MJ, Hopkinson NS, Schols AM, Moxham J, Polkey MI. A novel technique for nonvolitional assessment of quadriceps muscle endurance in humans. J Appl Physiol (1985). 2007 Sep;103(3):739-46.

38. Witt NJ, Zochodne DW, Bolton CF, Grand'Maison F, Wells G, Young GB, Sibbald WJ. Peripheral nerve function in sepsis and multiple organ failure. Chest. 1991 Jan;99(1):176-84.

39. Supinski GS, Callahan LA. Caspase activation contributes to endotoxininduced diaphragm weakness. J Appl Physiol (1985). 2006 Jun;100(6):1770-7.

40. Supinski G, Nethery D, Stofan D, DiMarco A. Comparison of the effects of endotoxin on limb, respiratory, and cardiac muscles. J Appl Physiol (1985). 1996 Sep;81(3):1370-8.

41. Herridge MS, Cheung AM, Tansey CM, Matte-Martyn A, Diaz-Granados N, Al-Saidi F, Cooper AB, Guest CB, Mazer CD, Mehta S, Stewart TE, Barr A, Cook D, Slutsky AS; Canadian Critical Care Trials Group. One-year outcomes in survivors of the acute respiratory distress syndrome. Feb 20;348(8):683-93.

42. Fan E, Dowdy DW, Colantuoni E, Mendez-Tellez PA, Sevransky JE, Shanholtz C, Himmelfarb CR, Desai SV, Ciesla N, Herridge MS, Pronovost PJ, Needham DM. Physical complications in acute lung injury survivors: a two-year longitudinal prospective study. Crit Care Med. 2014 Apr;42(4):849-59. 
43. Hall JB, Schweickert W, Kress JP. Role of analgesics, sedatives, neuromuscular blockers, and delirium. Crit Care Med. 2009,37:S416-S421.

44. Van den Berghe G, Schoonheydt K, Becx P, Bruyninckx F, Wouters PJ. Insulin therapy protects the central and peripheral nervous system of intensive care patients. Neurology. 2005;64:1348-1353.

45. Allen C, Glasziou P, Del Mar C. Bed rest: a potentially harmful treatment needing more careful evaluation. Lancet. 1999;354:1229-1233.

46. Callahan LA, Supinski GS. Sepsis-induced myopathy. Crit Care Med. 2009; 37:S354-S367.

47. Demoule A, Divangahi M, Yahiaoui L, Danialou G, Gvozdic D, Labbe K, Bao W, Petrof BJ. Endotoxin triggers nuclear factor-kappaBdependent up-regulation of multiple proinflammatory genes in the diaphragm. Am $J$ Respir Crit Care Med. 2006;174:646-653.

48. Reid MB, Lannergren $\mathrm{J}$, Westerblad $\mathrm{H}$. Respiratory and limb muscle weakness induced by tumor necrosis factor-alpha: involvement of muscle myofilaments. Am J Respir Crit Care Med. 2002;166:479-84.

49. Callahan LA, Stofan DA, Szweda LI, Nethery DE, Supinski GS. Free radicals alter maximal diaphragmatic mitochondrial oxygen consumption in endotoxin-induced sepsis. Free Radic Biol Med. 2001;30:129 -138.

50. Zarzhevsky N, Menashe O, Carmeli E, Stein H, Reznick AZ. Capacity for recovery and possible mechanism in immobilisation atrophy of young and old animals. Ann N Y Acad Sci. 2001;928:212-225.

51. Boczkowski J, Lanone S, Ungureanu-Longrois D, Danialou G, Fournier T, Aubier M. Induction of diaphragmatic nitric oxide synthase after endotoxin 
administration in rats: role on diaphragmatic contractile dysfunction. J Clin Invest. 1996;98:1550-1559.

52. Spooner CE, Markowitz NP, Saravolaz LD. The role of tumor necrosis factor in sepsis. Clin Immunol Immunopathol. 1992;62:11-17.

53. Fink $H$, Helming M, Unterbuchner C, Lenz A, Neff F, Martyn JA, Blobner M. Systemic inflammatory response syndrome increases immobility-induced neuromuscular weakness. Crit Care Med. 2008;36(3):910-916.

54. Sharma R, Anker S. Cytokines, apoptosis and cachexia: The potential for TNF antagonism. Int J Cardiol. 2002;85:161-171.

55. Hermans G, Clerckx B, Vanhullebusch T, Segers J, Vanpee G, Robbeets C, Casaer MP, Wouters P, Gosselink R, Van Den Berghe G. Interobserver agreement of Medical Research Council sum-score and handgrip strength in the intensive care unit. Muscle Nerve. 2012 Jan;45(1):18-25.

56. Latronico N, Shehu I, Guarneri B. Use of electrophysiologic testing. Crit Care Med. 2009 Oct;37(10 Suppl):S316-20.

57. Schweickert WD, Hall J. ICU-acquired weakness. Chest. 2007 May;131(5):1541-9.

58. Ali NA, O'Brien JM Jr, Hoffmann SP, Phillips G, Garland A, Finley JC, Almoosa K, Hejal R, Wolf KM, Lemeshow S, Connors AF Jr, Marsh CB; Midwest Critical Care Consortium. Acquired weakness, handgrip strength, and mortality in critically ill patients. Am J Respir Crit Care Med. 2008 Aug 1;178(3):261-8 .

59. Stevens RD, Marshall SA, Cornblath DR, Hoke A, Needham DM, de Jonghe B, Ali NA, Sharshar T. A framework for diagnosing and classifying intensive care unit-acquired weakness. Crit Care Med. 2009;37(10 Suppl):S299-308. 
60. Kleyweg RP, Van Der Meché FG, Schmitz PI. Interobserver agreement in the assessment of muscle strength and functional abilities in Guillain-Barré syndrome. Muscle Nerve. 1991 Nov;14(11):1103-9.

61. Gruther W, Benesch T, Zorn C, Paternostro-Sluga T, Quittan M, FialkaMoser V, Spiss C, Kainberger F, Crevenna R. Muscle wasting in intensive care patients: ultrasound observation of the M. quadriceps femoris muscle layer. $J$ Rehabil Med. 2008; 40: 185-189.

62. Baldwin CE, Bersten AD. Alterations in respiratory and limb muscle strength and size in patients with sepsis who are mechanically ventilated. Phys Ther. 2014 Jan;94(1):68-82.

63. Seymour JM, Ward K, Sidhu PS, Puthucheary Z, Steier J, Jolley CJ, Rafferty G, Polkey MI, Moxham J. Ultrasound measurement of rectus femoris cross-sectional area and the relationship with quadriceps strength in COPD. Thorax. 2009 May;64(5):418-23.

64. Dellinger RP, Levy MM, Rhodes A, Annane D, Gerlach H, Opal SM, Sevransky JE, Sprung CL, Douglas IS, Jaeschke R, Osborn TM, Nunnally ME, Townsend SR, Reinhart K, Kleinpell RM, Angus DC, Deutschman CS, Machado FR, Rubenfeld GD, Webb S, Beale RJ, Vincent JL, Moreno R; Surviving Sepsis Campaign Guidelines Committee including The Pediatric Subgroup. Surviving Sepsis Campaign: international guidelines for management of severe sepsis and septic shock, 2012. Intensive Care Med. 2013 Feb;39(2):165-228.

65. Metnitz PG, Moreno RP, Almeida E, Jordan B, Bauer P, Campos RA, lapichino G, Edbrooke D, Capuzzo M, Le Gall JR; SAPS 3 Investigators. SAPS 3-From evaluation of the patient to evaluation of the intensive care unit. Part 1: 
Objectives, methods and cohort description. Intensive Care Med. 2005;31(10):1336-44.

66. Moreno RP, Metnitz PG, Almeida E, Jordan B, Bauer P, Campos RA, lapichino G, Edbrooke D, Capuzzo M, Le Gall JR; SAPS 3 Investigators. SAPS 3-From evaluation of the patient to evaluation of the intensive care unit. Part 2: Development of a prognostic model for hospital mortality at ICU admission. Intensive Care Med. 2005;31(10):1345-55.

67. Vincent JL, Moreno R, Takala J, Willatts S, De Mendonça A, Bruining H, Reinhart CK, Suter PM, Thijs LG. The SOFA (Sepsis-related Organ Failure Assessment) score to describe organ dysfunction/ failure. On behalf of the Working Group on Sepsis-Related Problems of the European Society of Intensive Care Medicine. Intensive Care Med. 1996; 22:707-710.

68. Lin J, Fessell D, Jacobson J, Weadock W, Hayes C. An illustrated tutorial of musculoskeletal sonography: Part I, introduction and general principles. AJR Am J Roentgenol. 2000;175(3):637-45.

69. Shrikrishna D, Patel M, Tanner RJ, Seymour JM, Connolly BA, Puthucheary ZA, Walsh SL, Bloch SA, Sidhu PS, Hart N, Kemp PR, Moxham J, Polkey MI, Hopkinson NS. Quadriceps wasting and physical inactivity in patients with COPD. Eur Respir J. 2012; 40:1115-1122.

70. Hammond K, Mampilly J, Laghi FA, Goyal A, Collins EG, McBurney C, Jubran A, Tobin MJ. Validity and reliability of rectus femoris ultrasound measurements: Comparison of curved-array and linear-array transducers. $J$ Rehabil Res Dev. 2014;51(7):1155-64.

71. Sessler CN, Gosnell MS, Grap MJ, Brophy GM, O'Neal PV, Keane KA, Tesoro EP, Elswick RK. The Richmond Agitation-Sedation Scale: validity and 
reliability in adult intensive care unit patients. Am J Respir Crit Care Med. 2002;166:1338-1344.

72. De Jonghe B, Sharshar T, Lefaucheur JP, Authier FJ, Durand-Zaleski I, Boussarsar M, Cerf C, Renaud E, Mesrati F, Carlet J, Raphaël JC, Outin H, Bastuji-Garin S; Groupe de Réflexion et d'Etude des Neuromyopathies en Réanimation. Paresis acquired in the intensive care unit: a prospective multicenter study. JAMA. 2002 Dec 11;288(22):2859-67.

73. Günther CM, Bürger A, Rickert M, Crispin A, Schulz CU. Grip strength in healthy caucasian adults: reference values. J Hand Surg Am. 2008 Apr;33(4):558-65.

74. Puthucheary ZA, Rawal J, McPhail M, Connolly B, Ratnayake G, Chan P, Hopkinson NS, Phadke R, Dew T, Sidhu PS, Velloso C, Seymour J, Agley CC,Selby A, Limb M, Edwards LM, Smith K, Rowlerson A, Rennie MJ, Moxham J, Harridge SD, Hart N, Montgomery HE. Acute skeletal muscle wasting in critical illness. JAMA. 2013;310(15):1591-600.

75. Llano-Diez M, Renaud G, Andersson M, Marrero HG, Cacciani N, Engquist H, Corpeño R, Artemenko K, Bergquist J, Larsson L. Mechanisms underlying ICU muscle wasting and effects of passive mechanical loading. Crit Care. 2012 Oct 26;16(5):R209.

76. Ochala J, Ahlbeck K, Radell PJ, Eriksson LI, Larsson L. Factors underlying the early limb muscle weakness in acute quadriplegic myopathy using an experimental ICU porcine model. PLoS One. 2011;6(6):e20876.

77. Bednarík J, Vondracek P, Dusek L, Moravcova E, Cundrle I. Risk factors for critical illness polyneuromyopathy. J Neurol. 2005 Mar;252(3):343-51. 
78. Bierbrauer J, Koch S, Olbricht C, Hamati J, Lodka D, Schneider J, LutherSchröder A, Kleber C, Faust K, Wiesener S, Spies CD, Spranger J, Spuler S, Fielitz J, Weber-Carstens S.. Early type II fibre atrophy in intensive care unit patients with nonexcitable muscle membrane. Crit Care Med. 2012;40:647-650. 79. Monk DN, Plank LD, Franch-Arcas G, Finn PJ, Streat SJ, Hill GL. Sequential changes in the metabolic response in critically injured patients during the first 25 days after blunt trauma. Ann Surg. 1996 Apr;223(4):395-405. 80. de Bruin PF, Ueki J, Watson A, Pride NB. Size and strength of the respiratory and quadriceps muscles in patients with chronic asthma.. Eur Respir J. 1997;10(1):59-64.

81. Trappe TA, Lindquist DM, Carrithers JA. Muscle-specific atrophy of the quadríceps femoris with aging. J Appl Physiol. 2001;90:2070-4.

82. Sharshar T, Bastuji-Garin S, Stevens RD, Durand MC, Malissin I, Rodriguez P, Cerf C, Outin H, De Jonghe B; Groupe de Réflexion et d'Etude des Neuromyopathies En Réanimation. Presence and severity of intensive care unit-acquired paresis at time of awakening are associated with increased intensive care unit and hospital mortality. Crit Care Med. 2009 Dec;37(12):304753.

83. Borges RC, Carvalho CR, Colombo AS, da Silva Borges MP, Soriano FG. Physical activity, muscle strength, and exercise capacity 3 months after severe sepsis and septic shock. Intensive Care Med. 2015;41(8):1433-44.

84. Fan E, Dowdy DW, Colantuoni E, Mendez-Tellez PA, Sevransky JE, Shanholtz C, Himmelfarb CR, Desai SV, Ciesla N, Herridge MS, Pronovost PJ, Needham DM. Physical complications in acute lung injury survivors: a two-year longitudinal prospective study. Crit Care Med. 2014 Apr;42(4):849-59. 
85. Lewis MI, Lorusso TJ, Zhan WZ, Sieck GC. Interactive effects of denervation and malnutrition on diaphragm structure and function. $J$ Appl Physiol (1985). 1996 Nov;81(5):2165-72.

86. Le Bourdelles G, Viires N, Boczkowski J, Seta N, Pavlovic D, Aubier M. Effects of mechanical ventilation on diaphragmatic contractile properties in rats. Am J Respir Crit Care Med. 1994 Jun;149(6):1539-44.

87. Mendias CL, Marcin JE, Calerdon DR, Faulkner JA. Contractile properties of EDL and soleus muscles of myostatin-deficient mice. J Appl Physiol (1985). 2006 Sep;101(3):898-905.

88. Vesali RF, Cibicek N, Jakobsson T, Klaude M, Wernerman J, Rooyackers O. Protein metabolism in leg muscle following an endotoxin injection in healthy volunteers. Clin Sci (Lond). 2009 Dec 14;118(6):421-7.

89. Gosselink R, Needham D, Hermans G. ICU-based rehabilitation and its appropriate metrics. Curr Opin Crit Care. 2012 Oct;18(5):533-9.

90. Goodpaster BH, Carlson CL, Visser M, Kelley DE, Scherzinger A, Harris TB, Stamm E, Newman AB. Attenuation of skeletal muscle and strength in the elderly: The Health ABC Study. J Appl Physiol (1985). 2001 Jun;90(6):2157-65. 91. Autier P, Boniol M, Pizot C, Mullie P. Vitamin D status and ill health: a systematic review. Lancet Diabetes Endocrinol. 2014 Jan;2(1):76-89. .

92. Johnson AL, Smith JJ, Smith JM, Sanzone AG.Vitamin D insufficiency in patients with acute hip fractures of all ages and both sexes in a sunny climate. $J$ Orthop Trauma. 2013 Dec;27(12):e275-80.

93. Curry OB, Basten JF, Francis MJ, Smith R. Calcium uptake by sarcoplasmatic reticulum of muscle from vitamin D deficient rabbits. Nature. 1974;249:83-4. 
94. Boland R, de Boland AR, Ritz E, Hasselbach W. Effect of 1,25dihydroxycholecalciferol on sarcoplasmic reticulum calcium transport in strontium-fed chicks. Calcif Tissue Int. 1983;35(2):190-4.

95. Bischoff HA, Stahelin HB, Urscheler N, Ehrsam R, Vonthein R, PerrigChiello P, Tyndall A, Theiler R. Muscle strength in the elderly: its relation to vitamin D metabolites. Arch Phys Med Rehabil. 1999 Jan;80(1):54-8.

96. Visser M, Deeg DJ, Lips P. Low vitamin D and high parathyroid hormone levels as determinants of loss of muscle strength and muscle mass (sarcopenia): the Longitudinal Aging Study Amsterdam. J Clin Endocrinol Metab. 2003 Dec;88(12):5766-72.

97. Pfeifer M, Begerow B, Minne HW, Schlotthauer T, Pospeschill M, Scholz M, Lazarescu AD, Pollähne W. Vitamin D status, trunk muscle strength, body sway, falls, and fractures among 237 postmenopausal women with osteoporosis. Exp Clin Endocrinol Diabetes. 2001;109(2):87-92.

98. Dhanwal DK, Dharmshaktu P, Gautam VK, Gupta N, Saxena A. Hand grip strength and its correlation with vitamin D in Indian patients with hip fracture. Arch Osteoporos. 2013;8:158.

99. Glerup H, Mikkelsen K, Poulsen L, Hass E, Overbeck S, Andersen H, Charles P, Eriksen EF. Hypovitaminosis D myopathy without biochemical signs of osteomalacic bone involvement. Calcif Tissue Int. 2000 Jun;66(6):419-24.

100. Verhaar HJ, Samson MM, Jansen PA, de Vreede PL, Manten JW, Duursma SA. Muscle strength, functional mobility and vitamin D in older women. Aging (Milano). 2000 Dec;12(6):455-60.

101. Brancaccio P, Maffulli N, Buonauro R, Limongelli FM. Serum enzyme monitoring in sports medicine. Clin Sports Med. 2008 Jan;27(1):1-18. 
102. Wu AH, Perryman MB. Clinical applications of muscle enzymes and proteins. Curr Opin Rheumatol. 1992 Dec;4(6):815-20.

103. De Letter MA, van Doorn PA, Savelkoul HF, Laman JD, Schmitz PI, Op de Coul AA, Visser LH, Kros JM, Teepen JL, van der Meché FG. Critical illness polyneuropathy and myopathy (CIPNM): evidence for local immune activation by cytokine-expression in the muscle tissue. J Neuroimmunol. 2000 Jul 1;106(12):206-13.

104. Latronico N, Fenzi F, Recupero D, Guarneri B, Tomelleri G, Tonin P, De Maria G, Antonini L, Rizzuto N, Candiani A. Critical illness myopathy and neuropathy. Lancet.1996 Jun 8;347(9015):1579-82.

105. Druschky A, Herkert M, Radespiel-Tröger M, Druschky K, Hund E, Becker CM, Hilz MJ, Erbguth F, Neundörfer B. Critical illness polyneuropathy: clinical findings and cell culture assay of neurotoxicity assessed by a prospective study. Intensive Care Med. 2001, 27:686-693. 